\title{
EN TORNO AL URBANISMO IBÉRICO DE LA CONTESTANIA*
}

\author{
IBERIAN URBANISM IN CONTESTANIA
}

\author{
LORENZO ABAD CASAL \\ FELICIANA SALA SELLÉS \\ Universidad de Alicante
}

\begin{abstract}
Resumen. Se estudia la organización del poblamiento y el origen de los modelos de dispersión y distribución ibéricos, a partir de los trabajos históricos desarrollados en el marco de la antigua Contestania y de su entorno. Se documenta un cambio en los patrones de asentamiento a lo largo de la segunda mitad del primer milenio antes de nuestra era. Se destaca la existencia de un patrón urbano regular en los orígenes de algunos asentamientos, sobre todo costeros. Se estudian los fenómenos de modulación detectados, su organización interna y la de sus edificios más destacados.

Palabras clave. urbanismo, asentamientos, ibérico, fundación, Contestania
\end{abstract}

\begin{abstract}
The organization of the poblamiento and the origin of the models of Iberian dispersion and distribution, from the historical works developed within the framework of the old Contestania and of their surroundings are studied. Changes in the patterns of establishment throughout second half of the first millenium b.C. and the existence of a regular urban pattern in the origins of some establishments, mainly coastal, are documented. We paid attention to phenomena of modulation, internal organization and its more outstanding buildings.
\end{abstract}

Key words. urbanism, establishments, Iberian, foundation, Contestania

\section{INTRODUCCIÓN}

La larga tradición de estudios ibéricos valencianos nos permite contar con un amplio conjunto de publicaciones sobre esta cultura, y cabría esperar que entre ellas se incluyesen también las relacionadas con el urbanismo; sin embargo, esto es sólo en parte cierto. En las décadas iniciales del siglo, coincidiendo con la eclosión de los primeros trabajos sobre el mundo ibérico, y con la excavación de grandes superficies -poblados y necrópolis- en el litoral mediterráneo, la meseta y el valle del Ebro, se pusieron al descubierto amplias extensiones de numerosos yacimientos. Su publicación, o bien se realizó de manera parcial años más tarde, o bien no se ha llevado a cabo hasta el momento. Por lo que se refiere a las tierras valencianas fueron hitos básicos de esta etapa las excavaciones en la Bastida de les Alcusses y Covalta, en la provincia de Valencia, o las de Serreta y el Tossal de Manises en la de

\footnotetext{
* En su conjunto, este trabajo se incluye en el proyecto HUM2006-09874 del Ministerio de Educación y Ciencia. Programa Nacional de Investigación 2004-2007.
}

Alicante. Las memorias parciales publicadas en su momento permitieron hacerse una idea de su cronología y de las estructuras urbanísticas exhumadas, aunque sin la publicación completa no fue posible aprovechar toda la información. Algo parecido ocurrió en la zona de Murcia, donde excavaciones como las del poblado del Cabezo del Tío Pío, en Archena, se saldaron con una muy sucinta memoria.

En una etapa posterior, relacionada ya con la actividad de Domingo Fletcher y Miquel Tarradell al frente del Servicio de Investigación Prehistórica y el Laboratorio de Arqueología de la Universidad de Valencia, respectivamente, se procedió a la excavación de yacimientos tan importantes para la arqueología ibérica valenciana como Sant Miquel de Llíria y la Serreta, de los que se publicaron breves informes y estudios puntuales sobre cuestiones diversas, ninguna de ellas de asunto arquitectónico. Algo parecido ha seguido ocurriendo hasta fechas recientes; se han dado a conocer excavaciones concretas, de poca superficie, que resultan poco útiles para el 


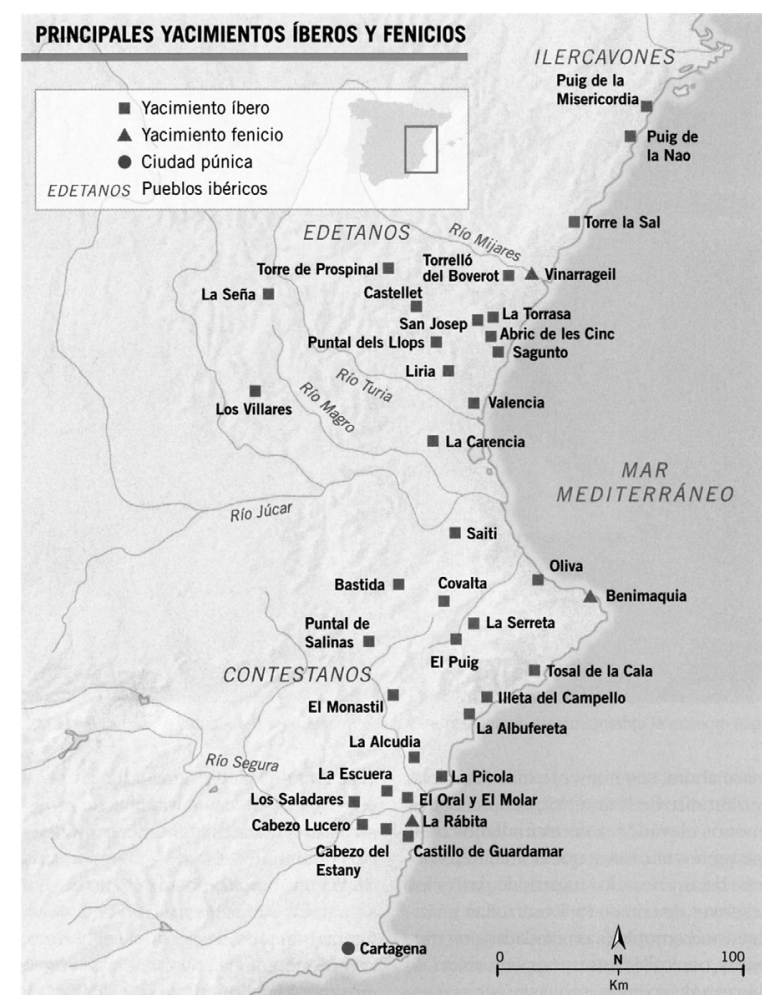

Figura 1: Principales yacimientos preibéricos e ibéricos valencianos.

estudio de los aspectos urbanísticos. La publicación de la obra de S. Nordström en el año 1967 sobre sus trabajos en La Escuera, aunque todavía en esa línea, supuso ya un cambio de rumbo importante.

En este marco de trabajos arqueológicos sin publicar, la aparición del libro de E. Llobregat Contestania Ibérica, en el año $1972^{1}$ constituyó un hito. Presentaba un resumen sucinto, pero suficientemente comprehensivo, de todos los yacimientos conocidos y excavados en la región identificada por él como la Contestania de las fuentes literarias: la comprendida entre el Júcar, el Segura y el Vinalopó, y sus yacimientos principales la Covalta, la Bastida, la Serreta, Puntal de Salinas, Tossal de la Cala, Tossal de Manises, La Escuera, l'Alcúdia, por citar los más conocidos. Con esta obra se ponía a disposición del investigador un conjunto de datos que, aunque sintético, resultaba indispensable para cualquier estudio posterior. Pero de manera inesperada, la publicación de este libro conllevó un resultado negativo; se pasó a considerar que sobre la Con-

1. En esta obra puede consultarse toda la bibliografía existente para los yacimientos contestanos hasta la fecha de su publicación, en muchos casos con una valoración crítica. testania ibérica estaba ya todo hecho y que era una pérdida de tiempo insistir en ella; tan sólo el trabajo de J. Uroz (1981) sobre aspectos económicos y sociales, no tratados por E. Llobregat, supuso un punto de avance. La urgente tarea de completar estos estudios quedó paralizada. Sirvió como modelo a seguir para las investigaciones que se plantearon pocos años después sobre áreas geográficas colindantes, como los trabajos de J. Uroz (1983) sobre Edetania y de P. Lillo (1981) sobre Murcia, aunque ninguna alcanzó la solidez arqueológica de la de E. Llobregat ${ }^{2}$.

En estos años sobrevino la eclosión de la arqueología espacial a raíz, sobre todo, de los Congresos de Arqueología Espacial de Teruel, a partir de modelos procedentes de los estudios geográficos anglosajones. El proyecto de este tipo más avanzado en el área a la que nos dedicamos fue el de la zona del Turia, llevado a cabo por Helena Bonet y Consuelo Mata, junto con otros investigadores, que constituye uno de los intentos más serios de arqueología espacial aplicada al mundo ibérico (Bonet y Mata, 1981; 2000; 2001; Bernabéu, Bonet, Guérin y Mata, 1986; Bernabéu, Bonet y Mata, 1987). Su metodología y marco teórico han servido de base para los trabajos posteriores que ya abarcan prácticamente todos los territorios iberos de norte a sur del País Valenciano. Entre ellos, los de A. Oliver (1996; 2001), F. Arasa (2001) y X. Allepuz (2001) para las comarcas de Castellón; el territorio de ArseSaguntum realizado por M. A. Martí (1998), el valle del río Cànyoles (Pérez Ballester y Borredà, 1998; Rodríguez Traver y Pérez Ballester, 2005) y la sierra de Enguera (Castellano et alii, 2005) en la provincia de Valencia, y, ya en Alicante, la montaña alicantina (Grau, 2002) y las comarcas meridionales y costeras (Moratalla, 2005).

Los estudios espaciales han contribuido al aumento del número de excavaciones en poblados de todos los territorios iberos valencianos durante las últimas décadas, ya sea reanudando excavaciones antiguas (Los Villares, la Bastida, La Escuera, el Puig de Alcoi, la Serreta, el Puig

2. A esto hay que añadir los numerosos trabajos de conjunto publicados por diversos autores en el marco de las obras de historia regional, tan frecuentes en España en las últimas décadas; entre ellos, los de E. Pla , 1981, M. Ros y J. Mas, 1980 y J. Uroz, 1985. Nuestra visión personal puede verse en A. Blanco y L. Abad, 1988, L. Abad y M. Bendala, 1990, L. Abad, 1987b y 1992. Una visión de conjunto de las facies de la cultura ibérica en el sur de la Contestania puede verse en F. Sala, 1995. 


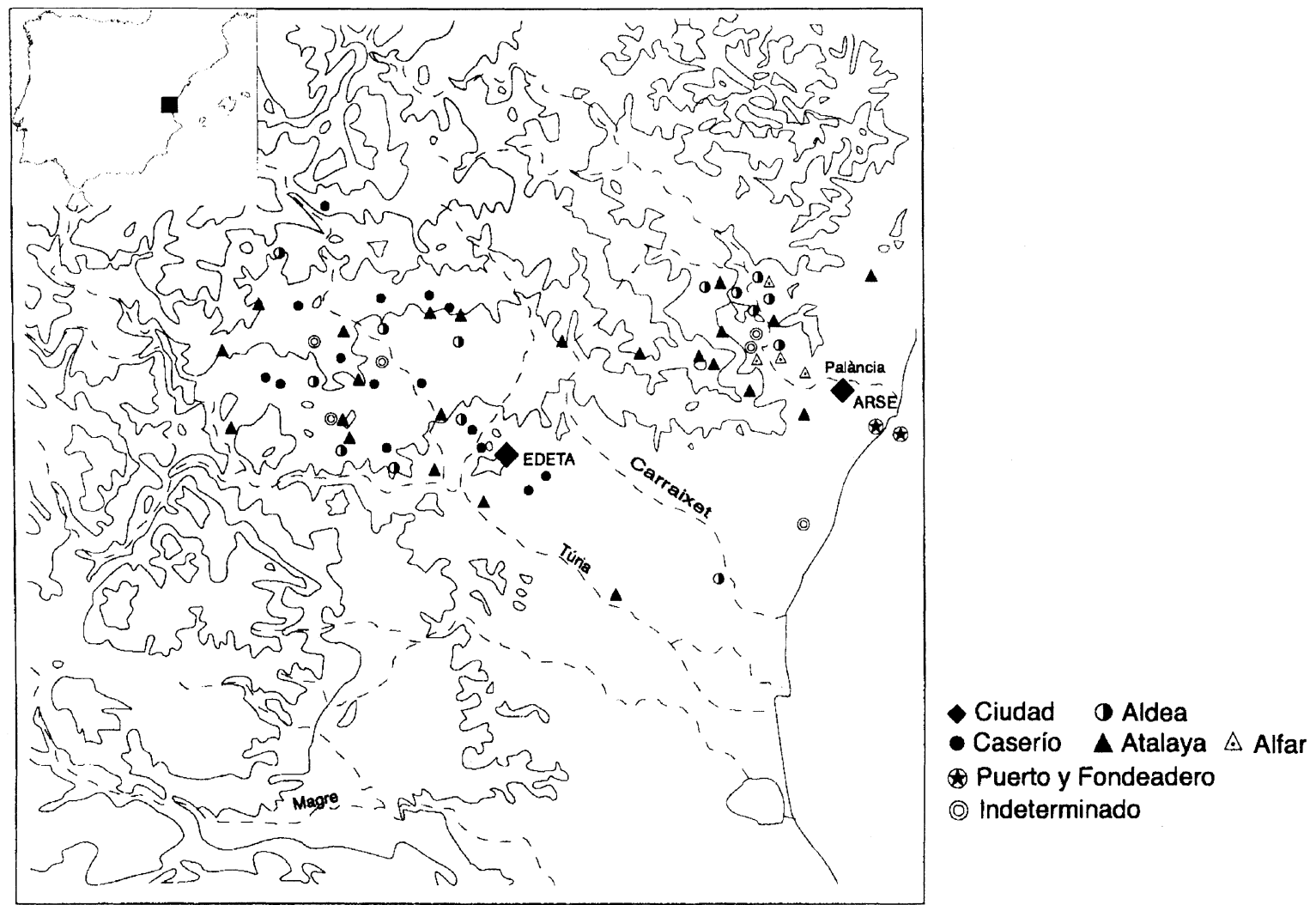

Figura 2: Ordenación del poblamiento en los territorios de Edeta y Arse, según Bonet y Mata, 2001 (datos de Arse de Martí Bonafé, 1998).

de la Misericordia, etc. ${ }^{3}$ ) ya sea iniciando excavaciones nuevas (El Oral, Puntal dels Llops, Castellet de Bernabé, La Seña, Puig de la Nau, etc. $)^{4}$. De una u otra manera, casi todos ellos han visto publicadas sus memorias de excavación. Todas incorporan un capítulo sobre el papel del yacimiento en el territorio, que ya resulta imprescindible, pero también apartados más o menos extensos dedicados al urbanismo y a la arquitectura. Este hecho ha traido como consecuencia que en esta área se disponga en la actualidad de una información notable sobre estos aspectos, con diferencia respecto a otros territorios iberos.

Nos encontramos, pues, en un momento sumamente interesante de los estudios ibéricos

3. Cf. Mata, 1991 para Los Villares; los trabajos en la Bastida siguen en curso aunque un avance del estado actual se presenta en Bonet et alii, 2005; para La Escuera, la Serreta y el Puig de la Misericordia, cf. respectivamente Abad y Sala (eds.), 2001; Olcina, 2005 y Oliver, 1994.

4. Cf. Abad y Sala, 1993 y 2001 para el Oral; para el Puntal dels Llops y Puig de la Nau remitimos a las respectivas últimas memorias de excavación de Bonet y Mata, 2002 y Oliver, 2006; para La Seña, cf. Bonet, 2000. en el País Valenciano. Sin embargo, falta todavía el estudio general que ofrezca la visión de conjunto sobre el urbanismo de los territorios valencianos y, a la vez, distinga los rasgos constructivos y urbanísticos particulares de cada comarca geográfica. Algo similar a lo realizado por C. Belarte (1997) para el nordeste peninsular y por J. A. Asencio (1995) para el valle del Ebro. En espera de esa síntesis, que requiere de una investigación más profunda, imposible de abordar aquí, planteamos una serie de cuestiones que tienen su origen en un trabajo redactado para un congreso y que nunca se llegó a publicar. Retomarlo ahora supone ganar en perspectiva, y nos permite observar en qué estado se encuentran los problemas allí expresados y cuáles son los que se han planteado desde entonces, puesto que el mayor número de excavaciones en poblados ibéricos del levante y sureste peninsular, y su publicación, han ido aportando nuevos datos que modifican considerablemente lo que se sabía del urbanismo ibérico. Nuestra intención es que esas dudas y reflexiones puedan servir como punto de partida para estudios futuros. 


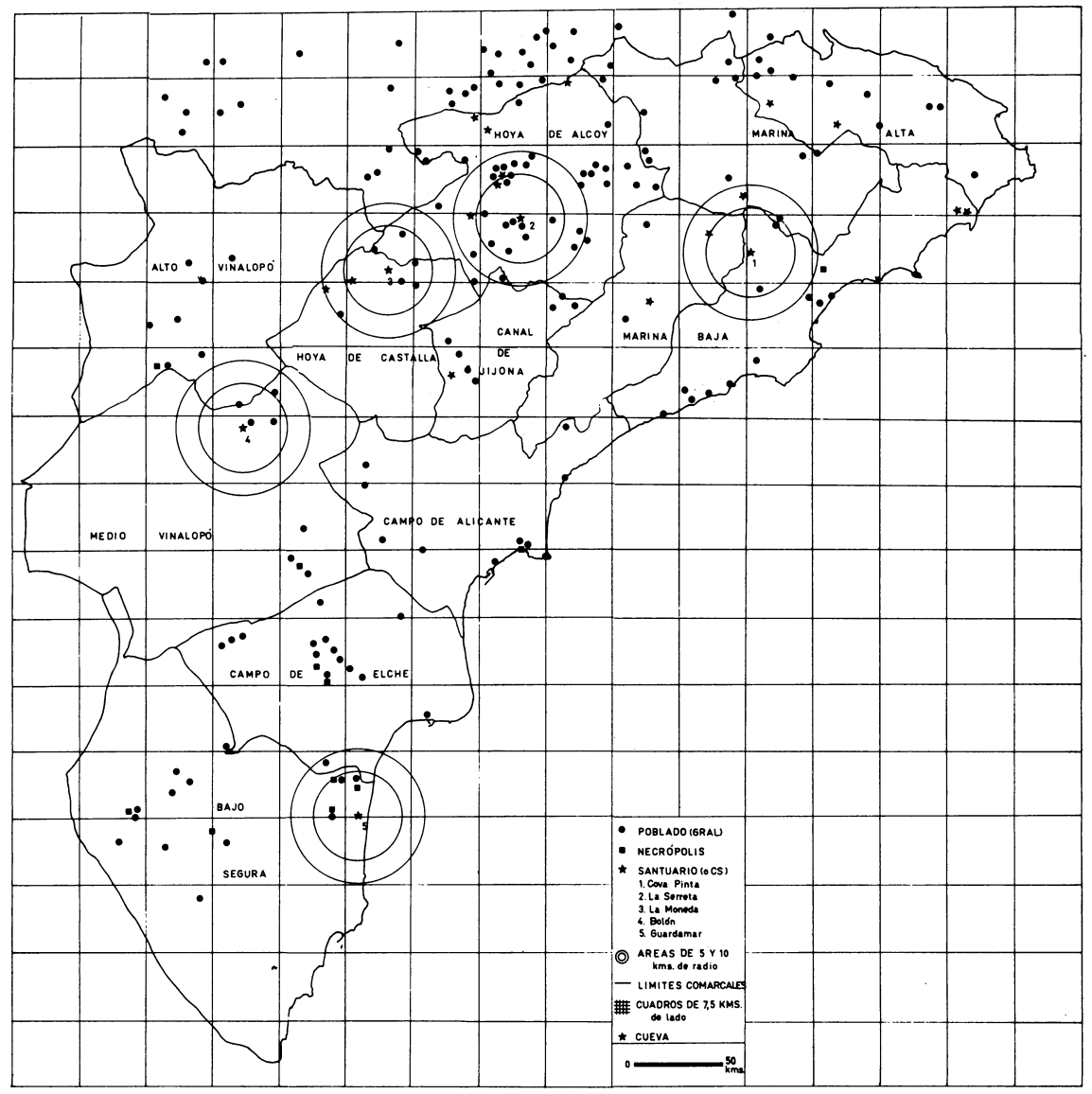

Figura 3: Densidad de poblamiento contestano, según Abad (1987a).

\section{LA ORDENACIÓN DEL TERRITORIO Y EL URBANISMO}

Como se ha dicho, es en la zona de Llíria donde primero se aplicaron los principios de la arqueología espacial. Para ello, se identificaron en primer lugar los yacimientos principales de la Edetania y se delimitaron sus respectivos entornos mediante la aplicación de los polígonos de Thyssen. A partir de ahí, se definieron las categorías de los asentamientos y se elaboró su jerarquía. Los establecimientos principales serían las ciudades, grandes recintos amurallados de tamaño igual o superior a 8 ha (Fig. 2). Este lugar lo ocupa Edeta, la capital del territorio edetano. A continuación vendrían una serie de recintos amurallados (oppida), clasificados como grandes, medianos y pequeños, según oscilen sus dimensiones entre 2 y 5 ha, 1 y 1,5 ha y alrededor de 0,5 ha, respectivamente. Por último, con unas dimensiones menores de 0,25 ha, estarían las atalayas y los caseríos; las primeras son fortificaciones con una torre que defiende su entrada, ubicadas en lugares elevados, de difícil acceso y amplia visi- bilidad, en tanto que los segundos se sitúan sobre pequeños cabezos de tierras bajas, con una finalidad económica muy diferente, tal y como atestigua su propia denominación. Edeta es el centro de una red de atalayas que facilitaba la llegada de información a la ciudad y que funcionó sobre todo a lo largo del Ibérico Pleno. Durante el Ibérico Tardío se abandonaron atalayas y caseríos y los núcleos de población tendieron a bajar al llano y a quedar desprovistos de muralla -aunque esto último no sea un fenómeno de riguroso cumplimiento-, hecho que los autores relacionan con el avance de la Romanización.

Estas conclusiones han sido extrapoladas al resto de territorios para configurar un modelo de patrón de asentamiento. Pero no todas las categorías inferiores en la jerarquía observada en la Edetania se documentan en los demás territorios iberos valencianos. Este dato permite plantear unas hipotéticas diferencias comarcales o geográficas, que convendría aquilatar en el futuro.

En la categoría de ciudades principales, se incluyen otros yacimientos valencianos como Arse (Sagunto), Kelin (Los Villares), Saiti (Játiva) 

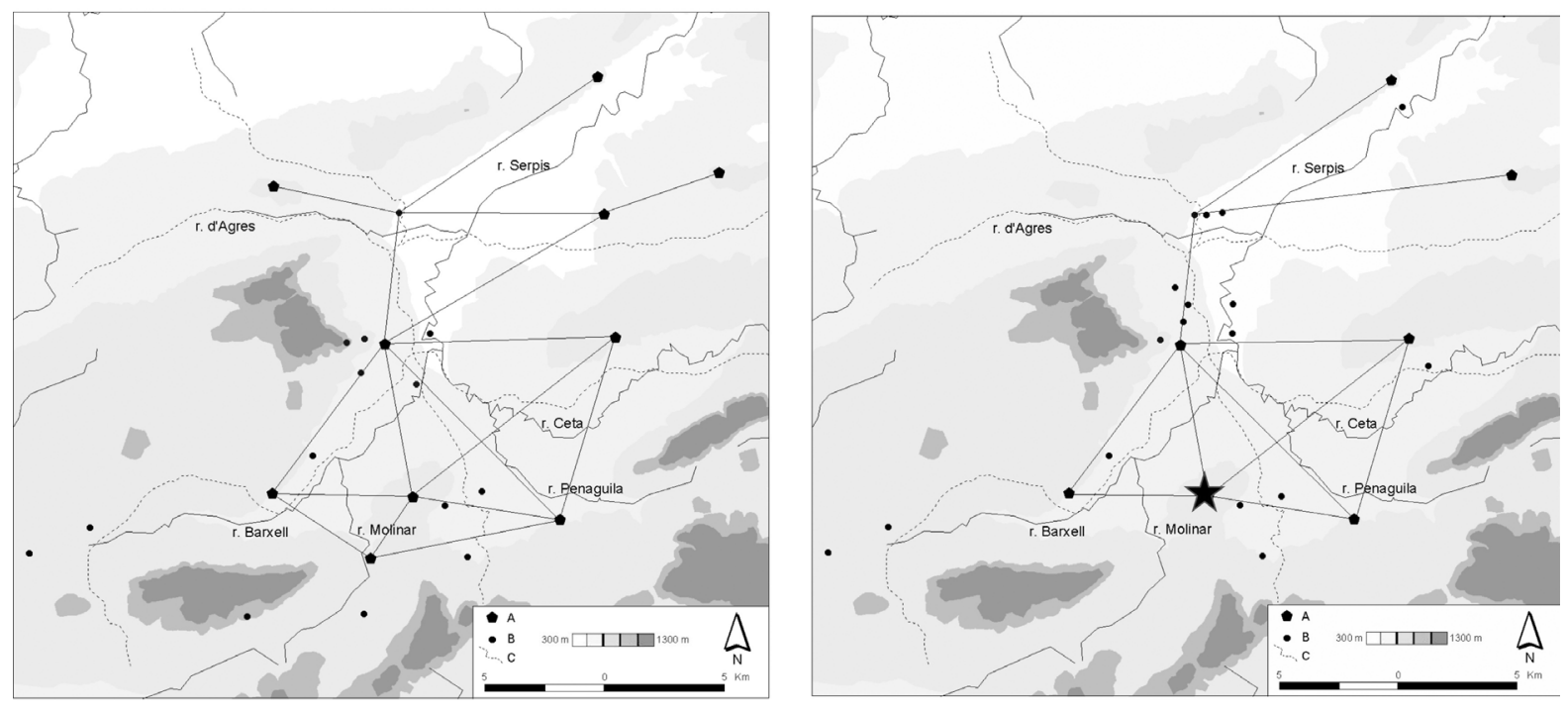

Figura 4: Organización territorial en los valles del Alcoià-Comtat durante los siglos IV a.C. (izquierda) y III a.C. (derecha, el asterisco mayor señala la capital), según Grau (2002).

e $\| l l i c i_{2}$ que compartirían con Edeta esa función de centro rector de sus respectivos territorios. La distribución de estos establecimientos es otro punto importante $y$, así, se puede distinguir entre las ciudades interiores, situadas en una posición preminente en su territorio, y las ubicadas en la franja costera donde, o bien constituyen puntos de salida al mar de vías de comunicación hacia el interior, caso del valle del Palancia a partir de Arse-Sagunto, o de llici con respecto a los valles del Vinalopó y del Segura, o bien son una puerta hacia otros territorios interiores más amplios, como Saiti, ubicada en la entrada del corredor de Montesa que facilita que la vía Heraclea se aleje de la costa para dirigirse hacia la meseta. En ese sentido, es interesante la observación de que no parece haber establecimientos capitales en el tramo costero de la vía Heraklea entre Saguntum y Saiti, hecho que los autores ponen en relación con la fundación de Valentia.

Saiti es, como se ha dicho, un importante nudo de comunicación en la vía Heraclea. La Bastida de les Alcusses, por ejemplo, debe su importancia en el territorio saetabitano a su posición relevante junto a ese camino. Sin embargo, desde Saiti también partía otra vía menor que se dirigía hacia el interior montañoso de la Contestania, donde en época ibérica plena existió un destacado poblamiento. A ello respondería la acumulación de yacimientos observada hace unos años en el eje Xàtiva-Alcoi (Abad, 1987a). Este primer intento de sistematización de los datos de poblamiento conocidos (Fig. 3) mostraba la mayor densidad de poblados iberos en la zona montañosa del norte de Alicante, con una especial concentración en torno a Alcoi-Cocentaina, 0,17 yacimientos por $\mathrm{km}^{2}$, en tanto que la densidad en la zona de Elx sólo alcanzaba los 0,12. Ello resultaba tanto más interesante si teníamos en cuenta que la densidad media de la Vega del Segura era de 0,022 y la del Vinalopó de 0,025 . Como indicábamos en un trabajo anterior (Abad, 1984), y el posterior estudio del territorio de la montaña alicantina de I. Grau (2002) ha confirmado, no sólo es posible defender la existencia de esa importante vía prerromana que desde Saiti llegaba hasta el interior de la montaña alicantina, sino que, incluso, podría prolongarse hasta el centro portuario ubicado en la albufereta de Alicante (Olcina et alii, 1998; Sala et alii, 2004).

El resultado de estas primeras observaciones personales permitieron en su momento trazar en la Contestania un cuadro similar al de la Edetania, aunque condicionado por la diversidad orográfica de la geografía alicantina, capaz de influir enormemente en una configuración cultural heterogénea (Abad, 1987a). La zona septentrional parecía organizarse alrededor del centro capital de Saiti, la única ciudad que acuña moneda en época ibérica y posee escultura. Las comarcas meridio-

5. El hecho de que tanto las inmediaciones de AlcoiCocentaina como las de Elx hubieran sido intensamente prospectadas influía sin ninguna duda, pero no creíamos que fuera un hecho determinante, ya que otras zonas igualmente bien prospectadas, como la Foia de Castalla o el río Vinalopó habían proporcionado un número de yacimientos considerablemente menor. 

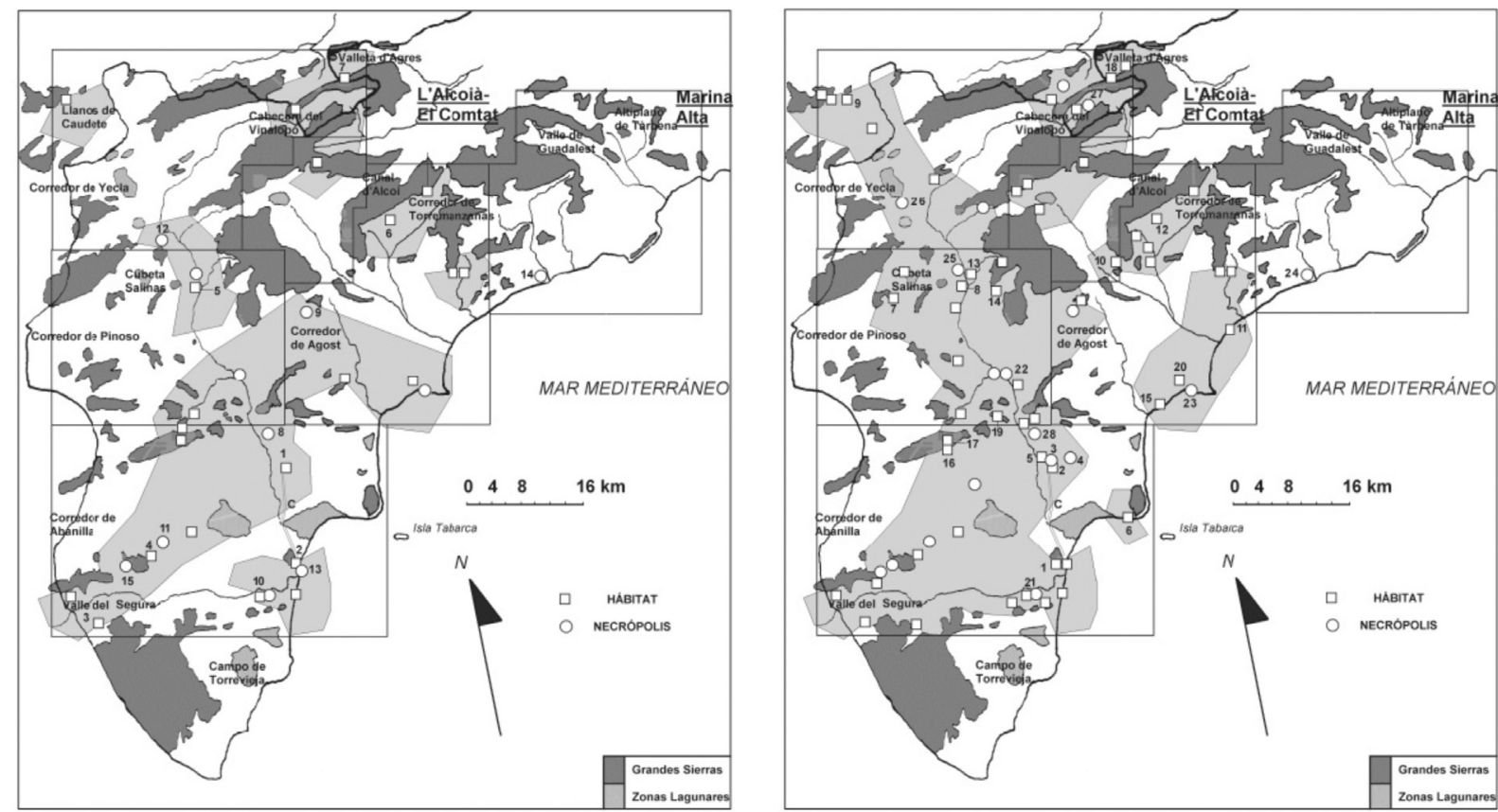

Figura 5: Poblamiento de la Contestania meridional en época antigua (izquierda) y en época plena (derecha), según Moratalla (2005).

nales gravitaban en torno a llici, cuyas dimensiones se cifraban tradicionalmente en torno a 10 ha y presentaba el conocido e importante conjunto escultórico ibérico. Sin embargo, los trabajos llevados a cabo en los años 90 en la Serreta han aportado una de las novedades más interesantes en este campo ${ }^{6}$. Las excavaciones en la muralla y en el interior del poblado pusieron de manifiesto que su extensión era bastante mayor de la que se suponía, lo que, unido a otros indicadores culturales, han hecho que este núcleo destaque en el poblamiento ibero de la montaña alicantina y pueda ser calificado como su centro capital (Olcina et alii, 1998). Entre esos indicadores culturales resaltaríamos ahora la presencia del santuario en el interior urbano ${ }^{7}$ y la existencia de escritura, por cuanto señalan la presencia de una elite.

Así, pues, en el análisis del territorio contestano la Serreta ha venido a sumarse en toda regla a Saiti e llici como la tercera ciudad ibera que capitalizó, en su caso, el poblamiento y la economía de las comarcas centrales alicantinas durante el siglo III a.C. Según el estudio de I. Grau (2002), a continuación de la capital tendríamos en la je-

6. Toda la bibliografía sobre dichos trabajos en la Serreta aparece recogida en Olcina, 2005.

7. Curiosamente, resulta parangonable en cuanto a fases de utilización con algunos del norte del País Valenciano. Cf. L. Abad, «La Romanización», en Alcoy. Prehistoria y Arqueología. Cien años de investigación, Alcoi, 1984. rarquía del poblamiento los oppida de mediano y pequeño tamaño, situados tanto en altura como a media ladera, de los que el Puig o la Covalta serían sendos ejemplos, y finalmente los pequeños enclaves rurales ubicados junto al curso de los ríos y cerca de los terrenos agrícolas (Fig. 4). A diferencia de la Edetania, faltan las atalayas, o pequeños enclaves situados en puntos estratégicos por su función defensiva, si bien es cierto que las labores de vigilancia las podían desempeñar perfectamente aquellos oppida en altura que acabamos de citar. En cualquier caso, existe un patrón en la ordenación del territorio basado en distintas categorías de enclaves, cuya actividad económica en sus respectivos entornos próximos sería asimismo diversa, como distinta sería también la condición social de sus habitantes.

Este orden territorial tiene su final tras el abandono de su capital, la Serreta, acontecido de forma súbita entre fines del siglo III e inicios del siglo II a.C., antes de que Saiti comenzara sus acuñaciones. Todo ello señala el principio de una reorganización espacial que bien pudo significar que este territorio pasase a depender de Saiti, aunque este tema, como tantos otros, necesitará de ulteriores comprobaciones arqueológicas. En este punto, conviene tener presente que cuando las fuentes escritas aluden a Saiti se refieren a la ciudad contestana de los siglos II y I a.C., y describen un enclave muy activo en lo económico y un nudo importante en la vía Hera- 
clea, que lo seguirá siendo en época romana. El camino que desde Saiti atravesaba la montaña alicantina para dirigirse hacia la costa sur alicantina pierde importancia ahora y se convierte en un simple camino local para una población ibera muy mermada en esta etapa ibérica final, ya que apenas hay yacimientos de esta cronología.

Este patrón de la montaña es semejante al de las comarcas meridionales contestanas y valle medio del Vinalopó, de acuerdo con las conclusiones de J. Moratalla (2005) (Fig. 5). En la primera categoría, la investigación sigue atribuyendo la capitalidad de este extenso espacio a llici entre otras razones, por sus dimensiones mayores que cualquier otro yacimiento del sur alicantino, a pesar de que recientemente este autor haya propuesto que la extensión de la ciudad ibérica quizá no superara las 6 ha, y que las 10 ha corresponderían, en realidad, al perímetro urbano de la ciudad romana. El papel de llici como 'capital' del sur se acrecienta ante la intensa relación que la ciudad parece mantener con yacimientos más meridionales y más occidentales en la etapa ibérica final, pues creemos que el ámbito contestano debió llegar, al menos en un momento avanzado, hasta la ciudad de Carthago Noua, superar con creces la línea del Vinalopó y extenderse por las comarcas vecinas de la meseta oriental (Abad, 1992). En este sentido, no estaría de más valorar nuevamente algunos elementos, como las áreas de difusión de la escultura contestana; y también los elementos contestanos que aparecen en la propia Cartagena y en los yacimientos de su entorno (Abad y Sanz, 1995), así como los de origen púnico que empiezan a atisbarse a partir del mejor conocimiento de no pocos materiales 'helenísticos' alcanzado en los últimos años en los yacimientos del centro y sur alicantinos, no todos ellos adscritos a las relaciones con Ibiza (Sala, 2001-02).

En cualquier caso, también en los territorios contestanos meridionales la jerarquía de establecimientos se completa con oppida de mediano y pequeño tamaño - La Escuera, con unas 2,5 ha, y El Puntal de Salinas, con 0,5 ha, constituirían sendos ejemplos- $y$ de pequeños enclaves rurales que se empiezan a constatar en terrenos llanos agrícolas, como el entorno de l'Alcúdia d'Elx o las vegas de las cubetas de Vinalopó. Hay, sin embargo, un matiz que diferencia la ordenación del territorio meridional del septentrional, y se basa en el supuesto de que l'Alcúdia ya fuese un centro capital desde la fase ibérica antigua (Moratalla, 2005, 99) inserto de alguna manera en un sistema polinuclear. Este modelo, por el contrario, se mantiene inalterado en la montaña alicantina desde la fase antigua, y sólo a inicios del siglo III a.C. se sustituye por un modelo de lugar central, papel que pasa a ser desempeñado por la Serreta, convertida ya en ciudad.

A partir de este momento, y al menos en algunas comarcas donde ha podido estudiarse el fenómeno con un cierto detenimiento, se produce tanto una notable reducción de población en áreas bastante extensas, como la montaña alicantina, el valle alto del Vinalopó o la vega baja del Segura, como la concentración del poblamiento en otras, especialmente en la franja costera septentrional o en áreas interiores próximas al litoral. Esto último va acompañado del desarrollo de ciertos yacimientos ya existentes, como ocurre en la Vila Joiosa, el área de la albufereta de Alicante, el entorno de l'Alcúdia d'Elx o el valle medio del Vinalopó en torno al Monastil de Elda. Probablemente, todo ello estuvo en relación con las transformaciones del hábitat tradicional ibero que ya se empiezan a materializar en el siglo I a.C. con esta redistribución poblacional. Por ello, no puede parecer casual que sean estos yacimientos los que algunos años después se convertieran en municipios y colonias romanas.

En definitiva, tendríamos que la Contestania ibérica antigua se ha organizado desde la fase ibérica según un sistema polinuclear que, por lo que sabemos, a inicios del siglo III a.C. es sustituido por un modelo de lugar central. En el poblamiento ibero contestano de época plena son tres las ciudades que regulan el territorio a partir del s. III a.C., lo que en términos espaciales puede significar que unas familias aristocráticas empiezan a sobresalir al ir incorporando nuevos espacios bajo su autoridad, haciendo que la extensión de los territorios que controlan sea cada vez mayor. La dicotomía del territorio contestano expresada por las fuentes escritas al destacar con sus alusiones sólo las ciudades de Saiti e llici parece cierta pero propia de los dos siglos finales de la cultura ibera, muy posiblemente en relación con ese nuevo reparto del territorio contestano entre Saiti e llici: las comarcas septentrionales pasan a formar parte del dominio de la primera y las meridionales continuan bajo el control de la segunda. Saiti con una extensión natural hacia el norte, hacia la Valentia del s. I a.C., e llici como una prolongación hacia Cartago Noua o hacia municipios del sureste de la meseta, como el Tolmo de Minateda, en Hellín.

\section{ASPECTOS URBANÍSTICOS}

Estas reflexiones sobre la ordenación territorial son posibles porque cada vez son más los po- 

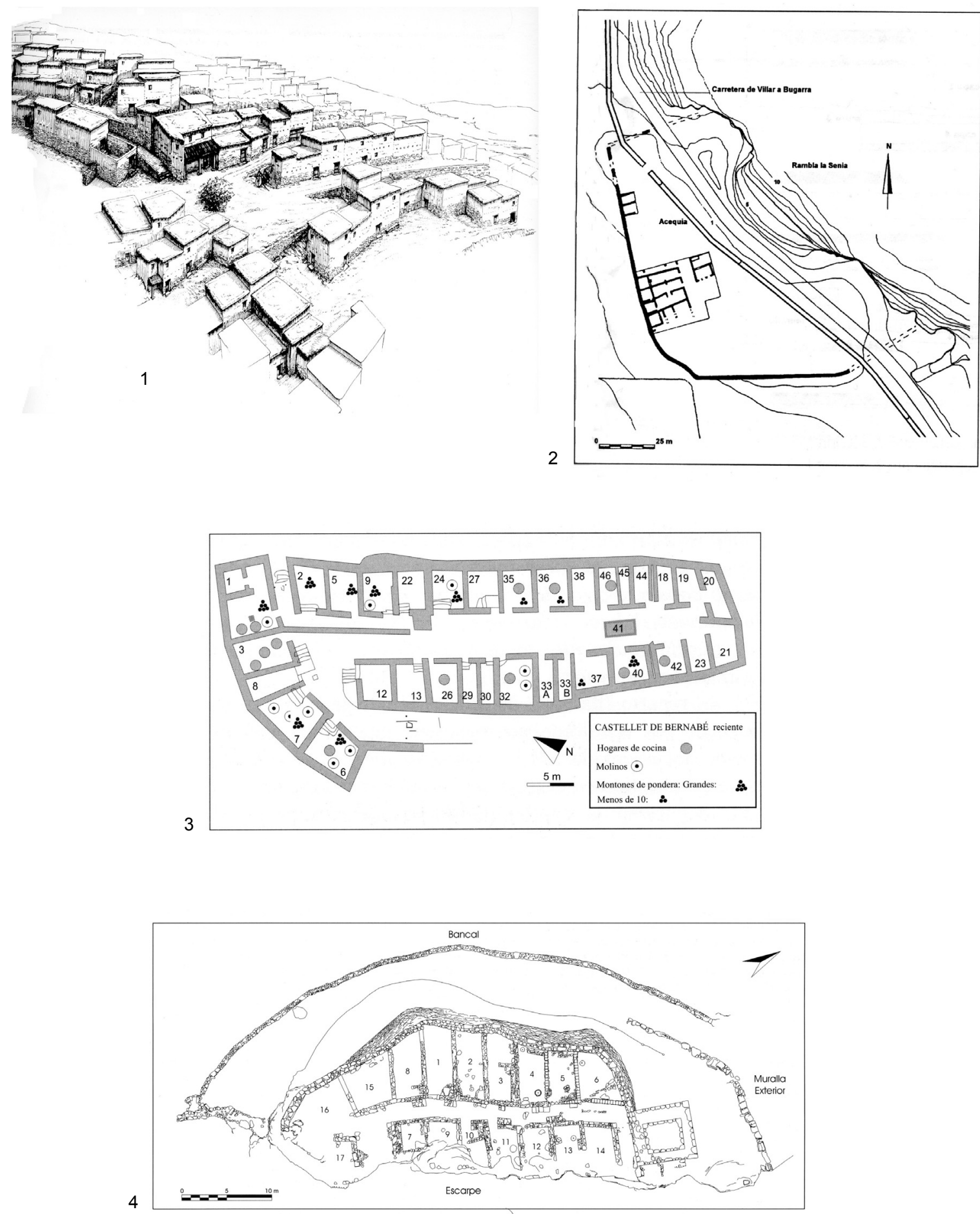

Figura 6: Urbanismo edetano: 1. Edeta (Bonet, 1995); 2. La Seña (Bonet, 2000); 3. Castellet de Bernabé (Guérin, 2003$) ; 4$. Puntal dels Llops (Bonet y Mata, 2004).

blados excavados en extensión. Disponemos de planos completos o medianamente amplios de El Oral, la Illeta dels Banyets, la Serreta, la Bastida, Puntal dels Llops, Castellet de Bernabé, Sant Miquel de Llíria, La Seña, Puig de la Nau y Puig de la Misericordia. De otros conocemos planos parciales, resultado casi siempre de una o varias campañas de excavación, que sólo aportan datos puntuales referentes a su propia organización o a las técnicas constructivas; entre ellos estarían poblados como El Puntal de Salinas, la Covalta, el Puig, La Escuera o el Tossal de les Basses. 
Con esta situación no es posible aún generalizar sobre la morfología del urbanismo, pero sí establecer una compararación entre los territorios.

Para el urbanismo edetano, contamos con los trabajos de H. Bonet, P. Guerin y C. Mata en los yacimientos del Camp del Túria. Lo que conocemos de su capital, Edeta-Llíria, epónimo de la regio, procede de una superficie excavada de unos $5000 \mathrm{~m}^{2}$ y en ella se incluyen 131 departamentos construídos en la ladera suroriental, de considerable pendiente (Fig. 6, 1). Ello obligaba a la realización de terrazas artificiales sobre las que se construyeron las casas, de manera que su parte posterior servía a su vez de muro de contención de las estructuras superiores; éstas se distribuían según las curvas de nivel y los espacios abiertos quedaban reducidos a estrechas callejuelas, pequeñas plazoletas y pasadizos más o menos irregulares. La estructura urbana de Sant Miquel de Llíria es un buen testimonio de lo que conocemos como urbanismo geomórfico (Bonet, 1995). Se trata de un tipo de urbanismo generalizado en época ibérica cuya ejecución depende del lugar en ladera elegido para ubicar el enclave, y no es el único en la Edetania. Un poblado pequeño como La Seña, construído en el llano, presenta un urbanismo bastante ortogonal, con calles espaciosas que se cruzan en ángulo recto (Bonet, 2000) (Fig. 6, 2). Finalmente estarían los caseríos y atalayas en los que, independientemente de su función, agrícola o militar, encontramos un urbanismo de calle central.

El ejemplo más claro del caserío es el de Castellet de Bernabé (Guérin, 2003) (Fig. 6, 3). De una extensión aproximada de $1000 \mathrm{~m}^{2}, \mathrm{y}$ rodeado por una muralla con un torreón junto a la puerta, todas las construcciones del poblado abrían a una calle central que permitía el tránsito rodado. El segundo yacimiento de interés es la atalaya o fortín del Puntal dels Llops (Bonet y Mata, 2002) (Fig. 6, 4), fundado a fines del siglo $\mathrm{V}$ a.C. para defender los intereses políticos y económicos de Edeta en su territorio, y destruído en momentos coincidentes con el inicio de la presencia romana. Más pequeño aún que el Castellet de Bernabé, pues sólo alcanza unos $650 \mathrm{~m}^{2}$, tiene planta ovalada irregular, con una calle central a la que se abren de manera más o menos perpendicular los diversos departamentos. Como en el Castellet de Bernabé, la entrada de corredor se encuentra flanqueada por un torreón cuadrangular, y en todo su perímetro la muralla estaba constituída por la pared trasera de las estancias. La calle se estrechaba a causa de los bancos y escaleras de piedra adosadas a las fachadas de los departamentos, lo que ha permitido confirmar la existencia de segundas plantas, algo que también se había comprobado en Edeta y Castellet Bernabé.

Por lo que se refiere al urbanismo contestano, hemos de partir de una información desigual. Por un lado, el urbanismo de la Bastida de les Alcusses y Covalta era conocido desde la publicacion de sus respectivas memorias de excavación en los años 60 y 70 (Fletcher et alii, 1965 y 1969; Vall de Pla, 1971). De su urbanismo se decía que constaba de una serie de departamentos rectangulares, agrupados de manera irregular en casas y manzanas, sin que pudiera rastrearse una disposición urbanística coherente. Por haberse excavado más en entensión, en la Bastida se conocían dos calles paralelas muy irregulares, orientadas en sentido este-oeste, a las que se abrían los departamentos, casi todos de forma rectangular; en esas dos calles principales incidían otras menores, perpendiculares y más estrechas, que separaban las posibles manzanas entre sí. La revisión de las excavaciones antiguas que han realizado $\mathrm{H}$. Bonet y $\mathrm{E}$. Dies para la apertura al público del yacimiento han demostrado que existe una organización urbana más regular de lo que se suponía, con edificios bastante grandes, un camino de ronda y tres calles principales paralelas (Bonet et alii, 2005; Dies y Álvarez, 1998) (Fig. 7, 1). Covalta se encuentra también en lo alto de una meseta similar, aunque de menores dimensiones, y se compone de estancias rectangulares, agrupadas en conjuntos mayores y dispuestas a ambos lados de una única calle principal, orientada en sentido este-oeste, a la que se abren también espacios irregulares tendentes a la forma rectangular y en los que desembocan callejones secundarios más estrechos. Al contrario que en la Bastida, no se ha podido avanzar en el conocimiento de su urbanismo y arquitectura, a pesar del loable esfuerzo realizado por M. Raga en la revisión de las excavaciones antiguas (Raga, 1996), que no se ha visto complementado con trabajos de campo.

Por otro lado, tendríamos la información procedente de las intervenciones arqueológicas de las últimas décadas. Los trabajos en la Serreta muestran un urbanismo geomórfico en el mismo territorio y en idénticas fechas, los siglos V y III a.C., que la Bastida y Covalta (Llobregat et alii, 1992; Olcina et alii, 2000) (Fig. 7, 2). Este es el modelo más frecuente en todas las comarcas contestanas. Lo encontramos en la ciudad interior, la Serreta, pero también en los oppida de su territorio. También está presente en los poblados costeros que eligen para su ubicación pequeñas elevaciones junto al litoral, y desarrollan el há- 


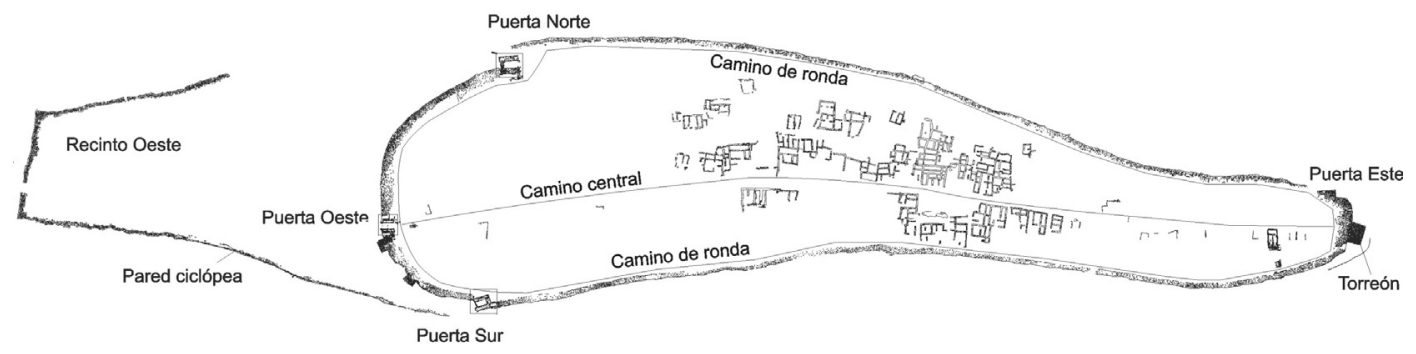

1

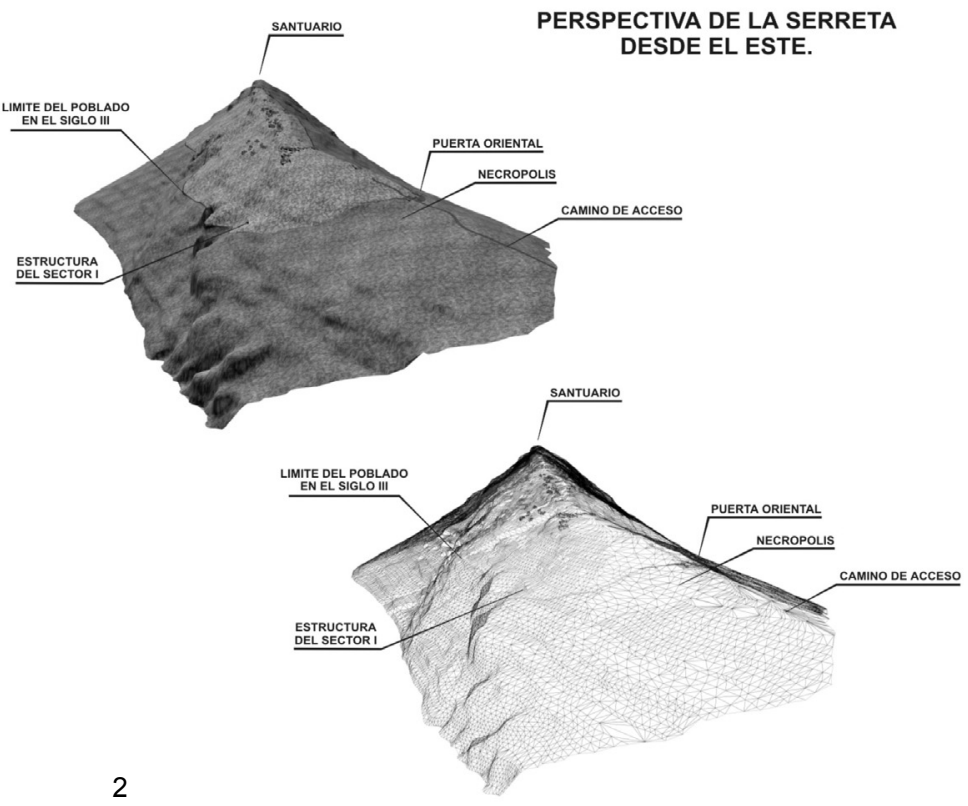

3
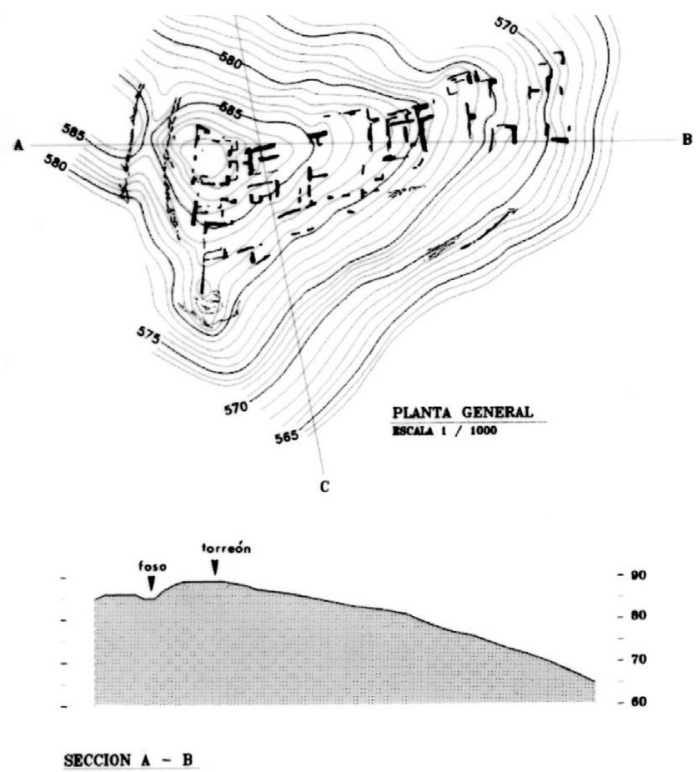

Figura 7: Urbanismo contestano geomórfico: 1. la Bastida de les Alcusses (modificado a partir de Bonet et alii, 2005); 2. la Serreta (Olcina, 2005); 3. Puntal de Salinas (Hernández y Sala, 1996). 


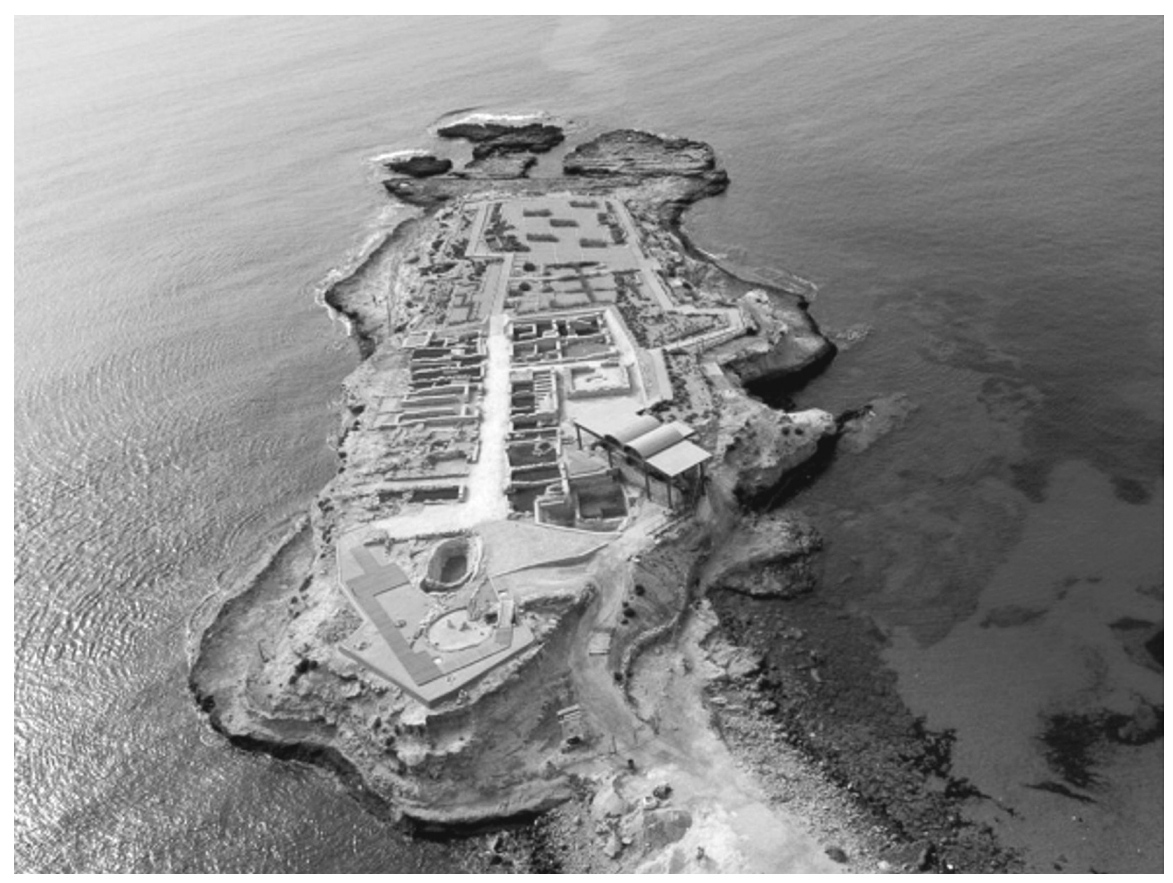

Figura 8: Urbanismo contestano regular en el s. IV a.C: la Illeta dels Banyets (foto MARQ).

bitat en las laderas de fuerte pendiente protegidas del mar, como el Tossal de la Cala (Tarradell, 1985), Cap Negret (Sala, 1990) y la Mallaeta ${ }^{8}$. Y también lo tenemos en el valle del Vinalopó en poblados como el Monastil y el Puntal de Salinas. Aunque todos ellos se hayan excavado muy parcialmente, la acusada orografía de los cerros donde se ubican no permite otro patrón urbano. En El Puntal de Salinas, la planimetría general realizada en 1992 ha confirmado la trama urbana condicionada por las curvas de nivel (Hernández y Sala, 1996), al haberse constatado que las construcciones exhumadas por J. M. Soler en 1955 son las de la terraza superior y que algunos muros de aterrazamiento son visibles en la ladera (Fig. 7, 3).

Independientemente de su tamaño y categoría, los poblados contestanos de altura presentan características más o menos similares; ocupan la cumbre o la parte superior de una ladera, preferentemente la solana, y se organizan a partir de unas calles principales que, cuando es posible -sobre todo cuando se ubican en las mesetas superiores-, tienden a la línea recta $y$, cuando no, se adaptan a las curvas de nivel. Estas calles se comunican entre sí por medio de otras secundarias, más estrechas y peor alinea-

8. Se trata del poblado que Llobregat recoge como Tossal del Moro y que actualmente está siendo excavado por un equipo hispano-francés dirigido por P. Rouillard. das, que en el caso de los poblados en ladera son frecuentemente empinadas y a veces escalonadas. Las casas se abren siempre que es posible a las calles principales, y en caso de pendientes muy fuertes se realizan aterrazamientos artificiales y recortes en las laderas para servir de asiento a parte de ellas. El modelo de urbanismo geomórfico se ha documentado hasta ahora en poblados de nueva planta fundados a fines del siglo $V$ a.C. Puesto que no conocemos los enclaves en ladera de la fase antigua, no podemos saber si existe o no una solución de continuidad respecto al urbanismo geomórfico presente en algunos poblados de la Edad del Bronce en Alicante. Durante el Bronce final del sureste, el urbanismo geomórfico se da en la Penya Negra de Crevillent y en el Castellar de Librilla, en Murcia, ambos en la cuenca del río Segura. En el valle alto de Vinalopó, el Cabezo Redondo de Villena es un excelente ejemplo de urbanismo geomórfico y de una sólida arquitectura doméstica en el Bronce Tardío. Existen calles principales que siguen el trazado de las curvas de nivel y callejones menores transversales para comunicarlas, algunos de ellos escalonados. Hay incluso espacios abiertos, a modo de plazas, en la confluencia de algunas calles ${ }^{9}$.

\footnotetext{
9. Según comunicación oral del profesor M. Hernández Pérez, a quien agradecemos el dato.
} 


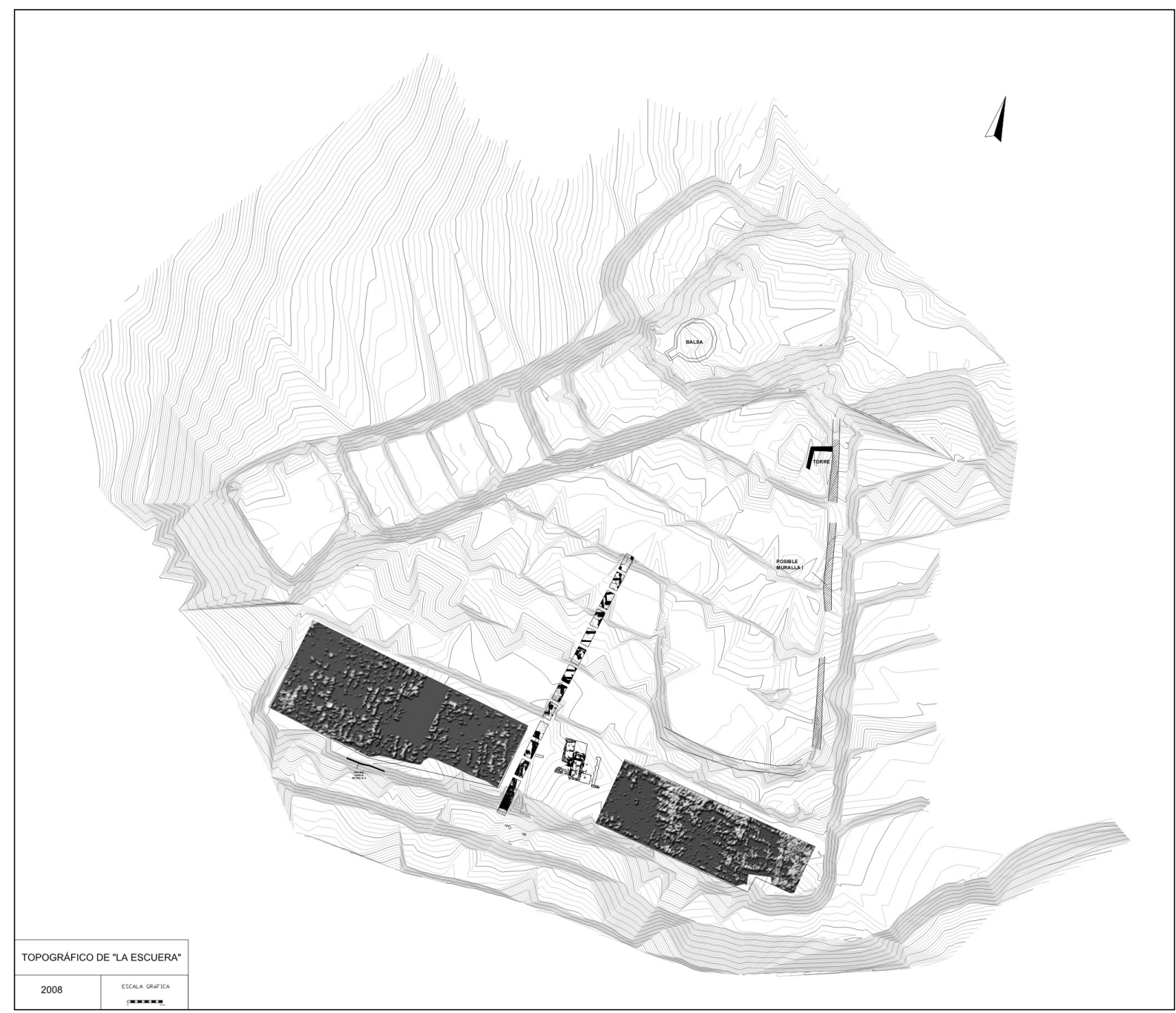

Figura 9: Yacimiento de la Escuera, con indicación de las excavaciones de S. Nordtröm y L. Abad, estructuras detectadas y los resultados de la prospección de georadar. Levantamiento topográfico de J. Sarabia y V. Cañavate.

Como en la Edetania, en la Contestania existe también un patrón urbano regular. El primero documentado fue la Illeta dels Banyets del Campello, gracias a los trabajos en extensión de E. Llobregat entre los años 70 y 80 . Con una cronología entre los siglos IV y III a.C., el enclave se sitúa sobre una pequeña península al borde del mar y presenta un plano de forma casi reticular, con dos calles principales que atraviesan el hábitat de forma longitudinal y se cruzan en ángulo aproximadamente recto con calles transversales (Olcina ed., 1997, con toda la bibliografía anterior de Llobregat). La intersección de esas calles parece conformar manzanas y barrios donde se distribuyen las construcciones domésticas, almacenes y talleres, y los edificios singulares (Fig. 8). Otro poblado que podría tener un urbanismo regular es La Escuera. A pesar de haberse ex- cavado una parte muy reducida ${ }^{10}$ (Nordström, 1967; Abad y Sala (eds.), 2001), el poblado se encuentra en una ladera de escasa pendiente, a pocos metros sobre la marjal de la desembocadura del Segura, lo que topográficamente permitiría un trazado de calles bastante regular (Fig. 9). Algo parecido podría deducirse del urbanismo en el Tossal de les Basses (Rosser, 2007), por hallarse ubicado sobre un pequeño cerro amesetado junto a la albufereta de Alicante. Sin embargo, el mejor ejemplo de este tipo de urbanismo lo ha proporcionado un poblado contestano de la fase antigua, El Oral, ya que su excavación en

10. En los últimos años se han reanudado los trabajos, con una prospección de georadar (Peña et alli, 2007) y con la limpieza de las excavaciones de S. Nordström. También se ha realizado la planimetría que se acompaña. 

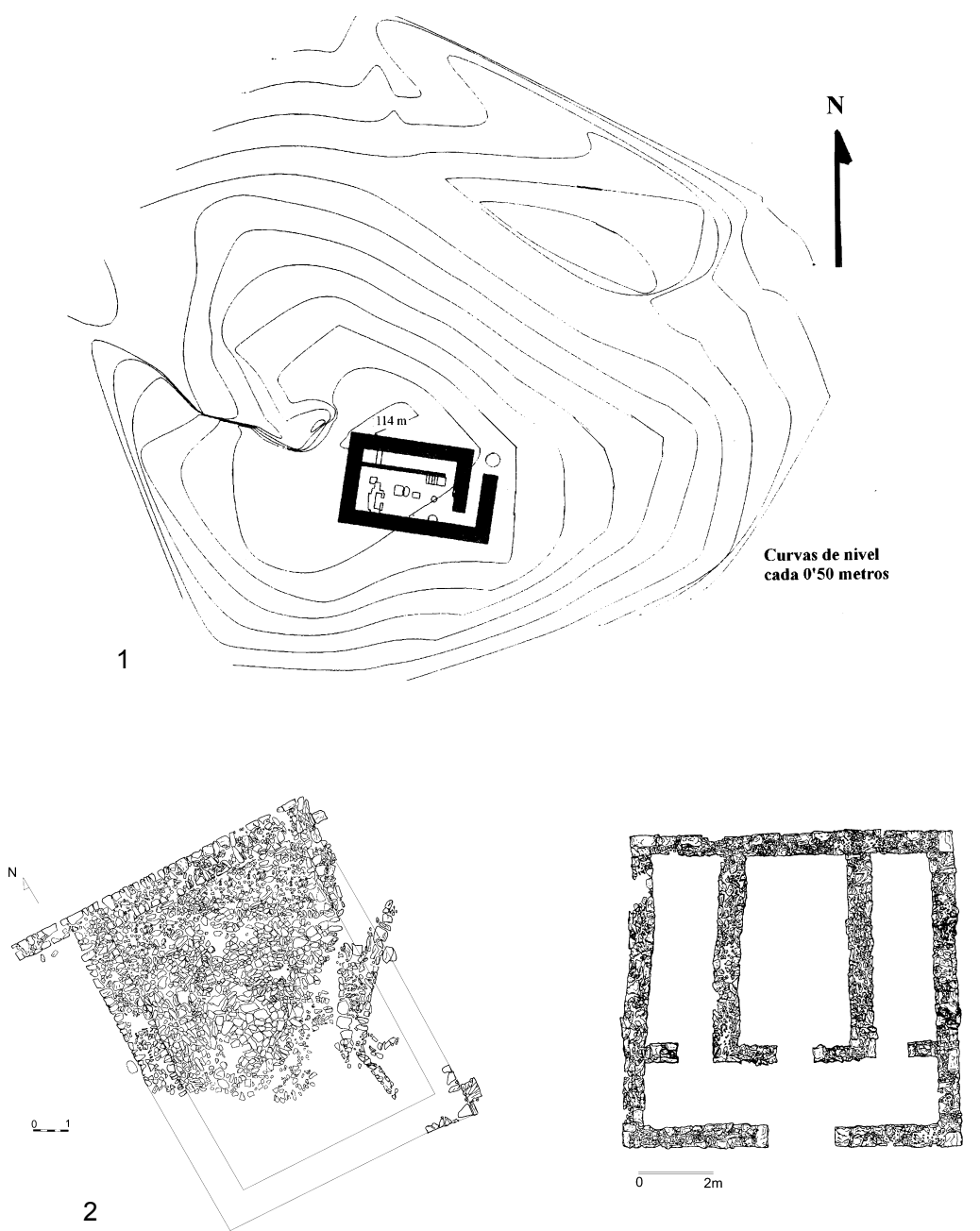

Figura 10: Edificios exentos: 1. el Perengil (Oliver, 2001); 2. I'Empedrola; 3. las Tres Hermanas (García y Moratalla, 1998-99).

área abierta ha ido proporcionando los datos que apuntan a la existencia de una ordenación racional y preestablecida del espacio urbano.

Por lo que respecta al urbanismo de calle central, en la Contestania ibérica no se conoce por el momento ningún ejemplo. Incluso para los poblados menores de una hectárea, como El Puntal de Salinas, se elige la ladera de un cerro. Las últimas excavaciones en el poblado de la Edad del Bronce de Terlinques, en Villena, están descubriendo una distribución de las estructuras en torno a una calle central. Si podemos admitir un precedente del urbanismo geomórfico ibero en el de los poblados de la Edad del Bronce, no se conocen poblados contestanos de calle central, por lo que sí cabe hablar en este punto de una solución de continuidad. Por el momento, el urbanismo en calle central quedaría restringido al valle del Ebro y las comarcas centrales valencianas, y no parece rebasar los límites meridionales de la Edetania. La distinta distribución geográfica resultante es de gran interés.

Por último, hay que mencionar la reciente aparición de un nuevo tipo de enclave constituido por un único edificio exento y aislado, cuyo papel en la ordenación del territorio deberá analizarse más profundamente (Fig.10). Los conocidos por el momento, el Perengil en Castellón (Oliver, 2001), l'Empedrola en Calp (Bolufer, Sala y Grau, e.p.) y Las Tres Hermanas de Aspe (García y Moratalla, 1998-99), no despejan la duda acerca de su hipotética función, pues se trata de edificios muy distintos a pesar de compartir una ubicación privilegiada en sus respectivos entornos. La función de vigilancia es indudable, y muy evidente en el caso de la torre vigía de l'Empedrola o el Perengil de Vinarós, pero también se habla de edificios ligados a algún tipo de culto gentilicio, como el de Las Tres Hermanas. 

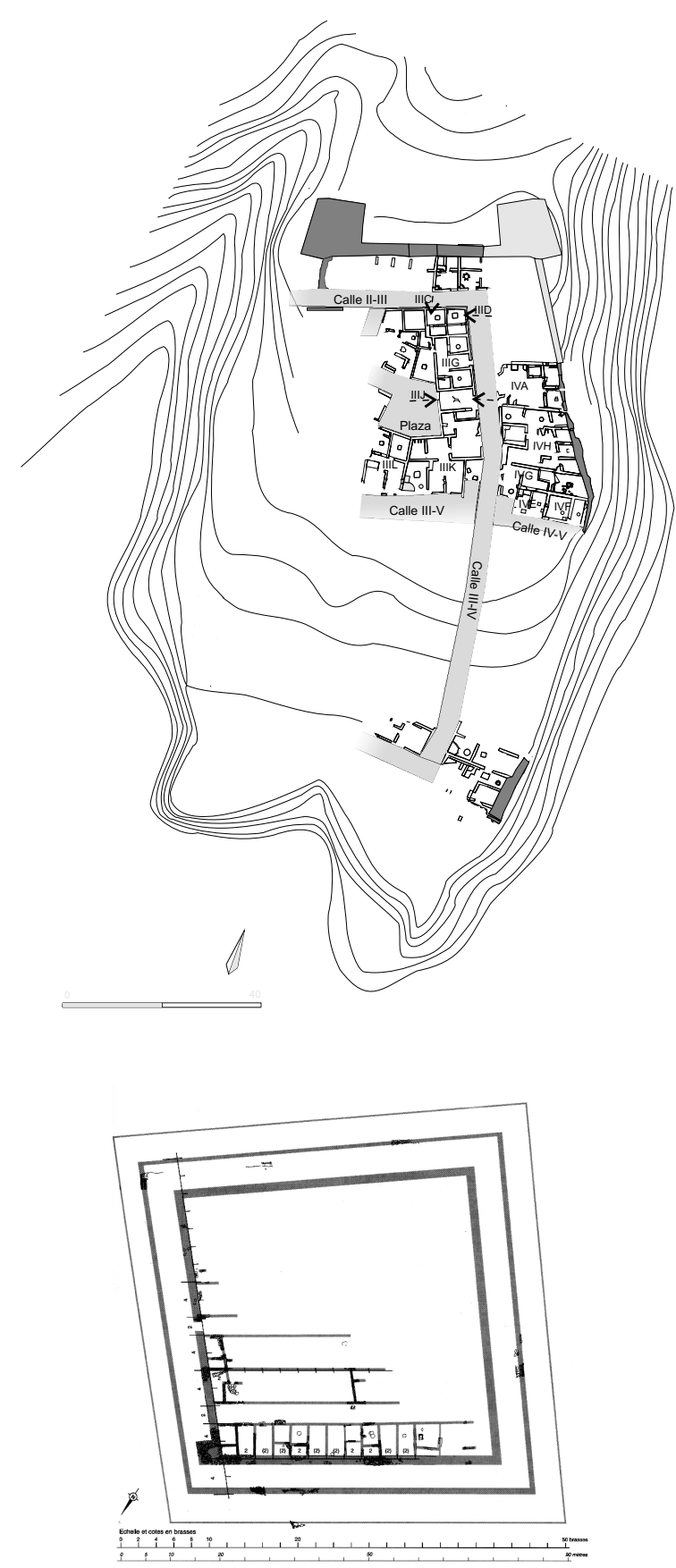

Figura 11: Urbanismo contestano regular del s. V a.C: 1. El Oral; 2. la Picola (Badie et alii, 2000).

\section{EL URBANISMO REGULAR EN POBLADOS COSTEROS CONTESTANOS ANTIGUOS}

De todo lo dicho parece deducirse que en los poblados contestanos coexisten al menos dos tradiciones urbanizadoras: la propia de los poblados de altura, con un urbanismo geomórfico en ladera, y un urbanismo regular o tendente a la retícula, que en un principio parecería más evo- lucionado y que, de aplicar un criterio estrictamente tipológico, se tendría que haber datado en un momento más avanzado. Dos poblados de la costa meridional contestana, El Oral y la Picola, demuestran su antigüedad y que ya en las últimas décadas del siglo $\mathrm{VI}$ y a lo largo de todo el s. $V$ a.C. el urbanismo regular estaba implantado en la tradición constructiva del poblamiento de la costa meridional contestana (Fig. 11).

El Oral se encuentra situado sobre una pequeña meseta en las estribaciones meridionales de la Sierra del Molar y dominaba en la antigüedad el estuario donde desembocaba el río Segura ${ }^{11}$. La excavación ha permitido hacerse una idea bastante clara de cómo se construyó un poblado de nueva planta a fines del siglo $\mathrm{VI}$ a. $C^{12}$. En un primer momento se acondicionó la superficie del cerro, por medio de una capa de tierra y piedra de no mucho grosor. Sobre esta capa, y por este orden, se levantaron los muros, se realizaron los pavimentos y se construyeron bancos y umbrales, aunque algunos de los bancos, que se encuentran revestidos por la misma capa que conformó el suelo, fueron realizados con anterioridad a él. Del estudio del conjunto de las estructuras conservadas parece deducirse que su trazado se realizó siguiendo unas pautas determinadas y la aplicación de uno o varios módulos muy concretos. Existe una unidad metrológica básica de $36,35 \mathrm{~cm}$ que hemos identificado con el pie, a la cual, o a sus múltiplos, se adaptan buena parte de las medidas de las diferentes estructuras. A partir de esta unidad pudieron identificarse otros varios módulos, de los cuales, los más frecuentes fueron uno de diez pies de largo por ocho o nueve de ancho, que se aplica a muchas de las habitaciones con hogar, y otro que viene a ser la mitad de éste, de diez por cinco pies, que corresponde a las estancias secundarias con ellos relacionadas. Pudo observarse también que la construcción de la muralla fue anterior a los edificios inmediatos, e incluso que se encontraba ya revestida por el interior en el momento en que se le adosaron las casas.

La división del espacio se realizó mediante el trazado de dos largas calles longitudinales y paralelas, comunicadas entre sí por otras transversales. La calle longitudinal oriental, la única

11. Sobre el paisaje de esta zona en la Antigüedad, cf. Estévez y Pina, 1984; Fernández Gutiérrez, 1986 y más recientemente, Barrier y Montenat, 2007.

12. La bibliografía sobre este poblado es ya bastante extensa. Por ello remitimos a las dos memorias de excavación: Abad y Sala, 1993 y Abad y Sala (eds.), 2001, ésta última con la referencia a las publicaciones anteriores. 
excavada, ofrece un ancho entre 9,5 y 11 pies de ancho. De las calles transversales ya hay tres documentadas. El resultado fue una especie de retícula irregular que delimitaba las manzanas de casas. Una de ellas, la número III (Fig. 11, 1), la única que se ha excavado en su casi totalidad, muestra cómo buena parte de sus estructuras fueron trazadas de una sola vez, obedeciendo a un plan preconcebido, ya que los muros maestros que configuran varias casas independientes están construídos al mismo tiempo, como atestigua la trabazón de sus ángulos, en tanto que los muros interiores, que delimitan las diferentes habitaciones de una misma casa, han sido realizados con posterioridad, adosándose a los principales; pero incluso en este caso se observa que estos muros de subdivisión interna presentan una alineación similar, lo que permite suponer que también ellos fueron trazados de acuerdo con un plan preconcebido. De todo ello puede deducirse que el poblado de El Oral -o al menos su mayor parte- se construyó de una sola vez, en un plazo de tiempo no muy largo, según un plan previamente establecido, y que en la erección de sus diferentes edificios se utilizó un conjunto de módulos determinados, basados en el pie y sus múltiplos.

Relativamente próximo al Oral, en el límite septentrional de la gran área inundada que fue la depresión meridional, estuvo el enclave de la Picola (Badie et alii, 2000) (Fig. 11, 2). De planta cuadrangular, tiene una muralla provista de foso y antemural, y un urbanismo regular con estancias alargadas abiertas a las calles. Partiendo del desconocimiento de paralelos satisfactorios tanto en el mundo ibérico como fuera de él, los excavadores de la Picola ven bastantes similitudes entre su urbanismo regular y el de Olbia, con un reparto comparable de las viviendas en bloques alargados y simétricos. En la pequeña fortificación de Pain du Sucre, también cerca de Marsella, las dimensiones de las estancias son parecidas a las de la Picola. En el Mar Negro, también se detectan pequeños enclaves costeros fortificados de planimetría regular, como la Picola. La metrología de la arquitectura, basada en un pie de 29,6/29,7 cm, es la misma que en Ampurias y Ullastret. Asimismo, en Ampurias y la Picola se constata la unidad de medida griega que valía 6 pies o 4 codos, la braza u orguïa, y el módulo de 5 brazas. Por todo ello, los excavadores ven en el plano regular de la Picola y sus viviendas alargadas el reflejo de un patrón de urbanismo griego (Badie et alii, 2001, 128-133).

El fenómeno de modulación que sirve de base para el trazado de asentamientos ibéricos, preferentemente de nueva planta, y que también se observa en la refacción de algunos asentamientos anteriores, ya ha empezado a atestiguarse en otros yacimientos ibéricos, como han demostrado F. Gusi y A. Oliver y H. Bonet y C. Mata para algunos yacimientos castelloneneses y valencianos. El Oral y la Picola van un poco más allá, pues muestran un fenómeno de urbanización ex novo por parte de unas poblaciones que poseían ya la tecnología adecuada $y$, sobre todo, la representación mental de lo que debía ser un poblado de nueva creación. Es así a fines del siglo VI en El Oral, y lo tenemos de nuevo a fines del siglo $V$ a.C. en la Picola. Aquí podrían ser comerciantes foceos, según sugieren los excavadores (Badie et alii, 2001, 259); para El Oral, M. Bendala lanzó la idea de un oikistés, un fundador, que es una forma de explicar la existencia de esos principios reguladores a los que hemos hecho referencia, característicos de las fundaciones coloniales de nueva planta, como puede observarse, por ejemplo, en algunas ciudades de la Magna Grecia. Realmente, las posibilidades de interpretación que se desprenden de este hecho, incluso para el estudio de los momentos más antiguos de la iberización, son muy importantes, pero no es éste lugar para desarrollarlas ${ }^{13}$.

En la Vega Baja del Segura, el conocimiento de la arquitectura protohistórica e ibérica ha experimentado un gran avance a partir de las excavaciones en la colonia fenicia de la Fonteta, situada junto a la desembocadura del Segura ${ }^{14}$. Con anterioridad, sólo se conocía la existencia del Cabezo del Estaño (García Menárguez, 1995) en la margen derecha del río Segura, a un par de kilómetros de la colonia fenicia, justo enfrente del Oral. Aunque fue destruído en buena parte por una cantera, la excavación de urgencia consiguió salvar una parte de su fortificación y algunas casas; estas últimas mostraban plantas y pavimentos muy parecidos a los que ya se conocían en EI Oral. En el momento de estos hallazgos, todavía sin saber de la cercana presencia de la colonia fenicia, la existencia de cerámicas propiamente fenicias en el Cabezo, algo que no aparecía en El Oral, elevaba la cronología del asentamiento al siglo VII a.C. y marcaba la diferencia cultural

13. Véase unas primeras reflexiones al respecto en nuestra aportación al reciente congreso Phönizisches und punisches Städtewesen, organizado por el Instituto Arqueológico Alemán y celebrado en febrero de 2007 en Roma.

14. Además de los primeros avances (González Prats, 1999; González Prats et alii, 1999; Azuar et alii, 1998; 2000), acaba de publicarse la primera memoria de las excavaciones (Rouillard et alii, 2007). 


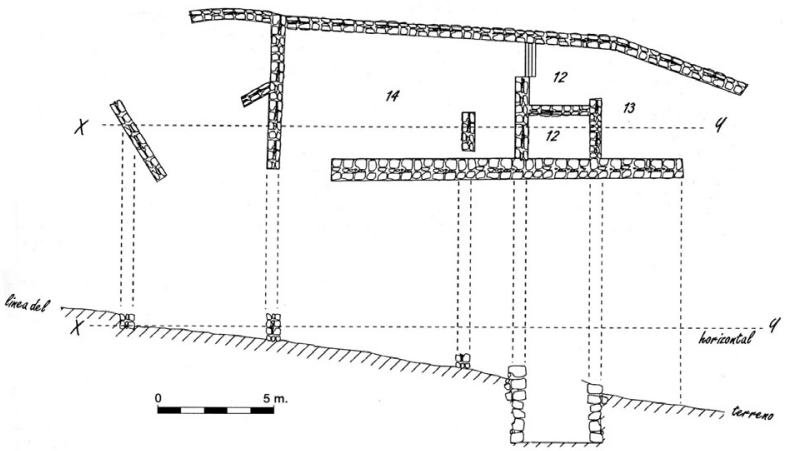

1
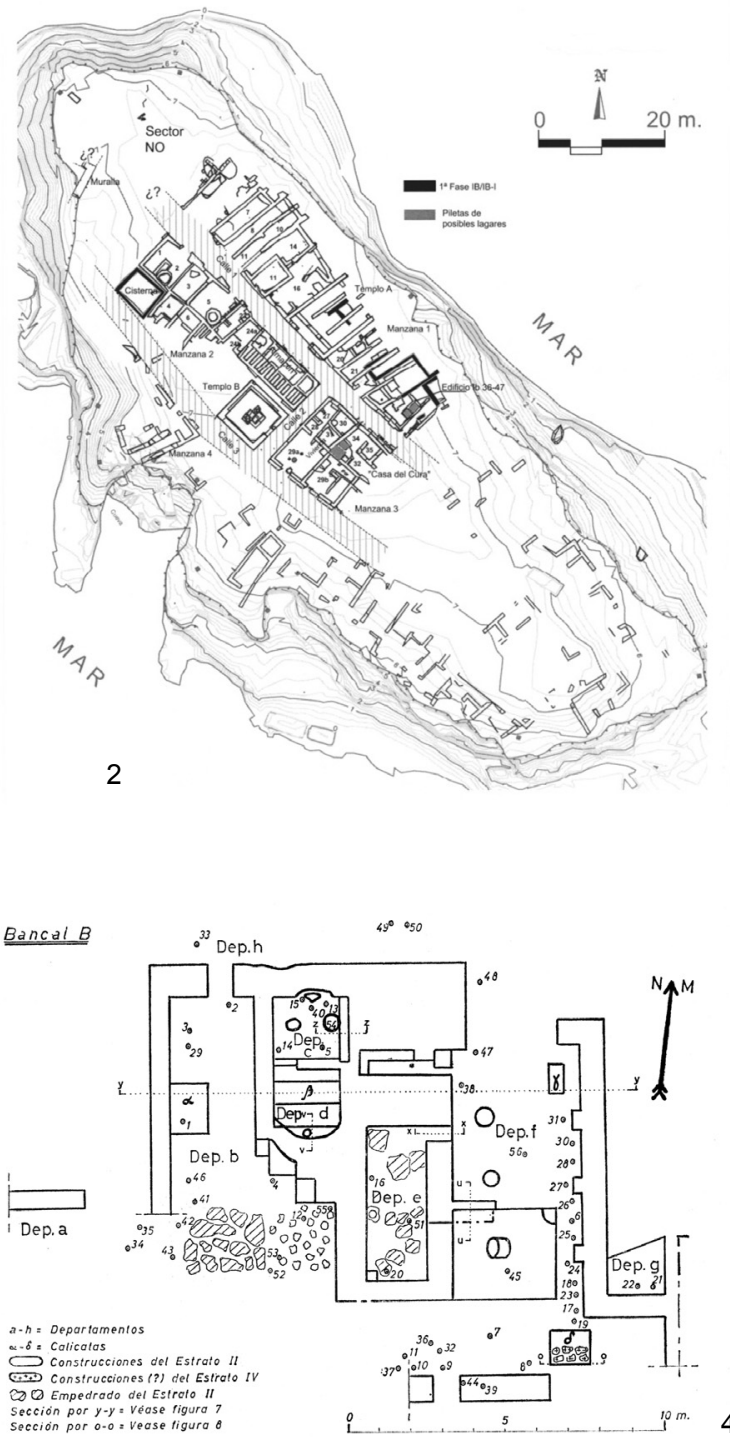

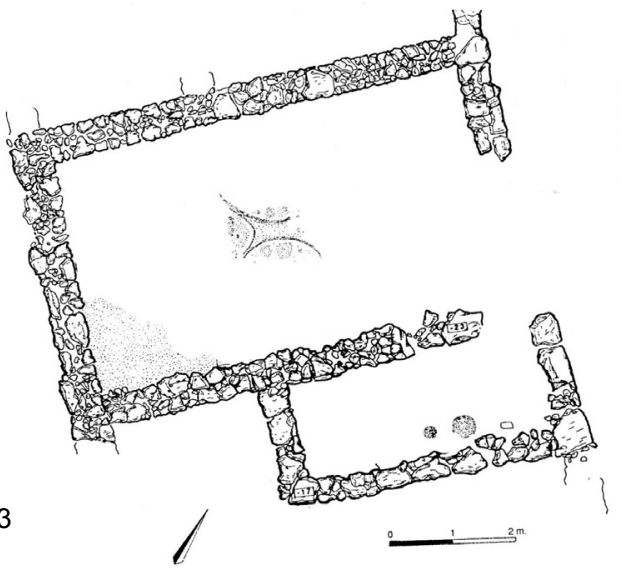

Figura 12: Edificios de culto de carácter urbano: 1. templo de Edeta (Bonet, 1995); 2. Templos a y b de la Illeta dels Banyets (Olcina, 2005); 3. edificio IIIJ de El Oral; 4. templo de La Escuera (Nordström, 1967).

con el poblado ibérico antiguo. Pero la ocupación del Cabezo del Estaño fue corta, como en El Oral, poco más de un siglo, al final del cual ambos asentamientos son abandonados para siempre. Este precedente en el Cabezo del Estaño venía a ser un nuevo testimonio de que El Oral era un eslabón más en un proceso de extensión del poblamiento por la zona, articulado mediante pequeños establecimientos de corta vida, quizá en torno a un núcleo mayor -o tal vez no- de los que sólo unos pocos llegaron a cristalizar en los grandes poblados de época ibérica plena.

El inicio de las excavaciones en el yacimiento de las dunas de Guardamar descubrió la existencia de la colonia fenicia, y con ella los precedentes inmediatos de la arquitectura de El Oral. Ésta es ya una arquitectura ibérica, pero mantiene en gran medida la tradición constructiva fenicio-púnica de la colonia. Un ambiente muy distinto al de la Picola, donde sus excavadores ven en la metrología de las construcciones y sus plantas, así como en la propia fortificación, una tradición constructiva más bien griega. Púnica o griega es una cuestión que poco debe importarnos ahora, porque lo interesante es haber constatado que el urbanismo regular aparece en establecimientos costeros contestanos situados en puntos clave para el tránsito marítimo, coincidiendo con los buenos embarcaderos que favorecen los intercambios comerciales y el contacto 
entre iberos y comerciantes, que pudieron convivir durante años instalados en barrios portuarios, o pasar largas temporadas mientras esperaban la llegada del buen tiempo.

En los siglos IV y III a.C., el urbanismo regular lo tenemos otra vez en la llleta dels Banyets. De nuevo es un enclave marítimo, abocado al mar y a las relaciones comerciales, como están demostrando los trabajos de musealización dirigidos por el MARQ y el Servicio de Arquitectura de la Diputación de Alicante. El Tossal de les Basses y La Escuera, en los que hemos supuesto la existencia de un urbanismo regular, están también en buenos desembarcaderos, la albufereta de Alicante y la desembocadura del río Segura, respectivamente. Su carácter marítimo y comercial ha quedado de manifiesto por el elevado número de importaciones en el registro material de sus excavaciones. Podemos decir, por tanto, que el modelo urbano regular pervive en la fase plena en establecimientos costeros puntuales que coinciden con buenos embarcaderos.

A partir de la Illeta dels Banyets, los enclaves de la costa septentrional alicantina -la Vila, Tossal de la Cala, Cap Negret, Penyal d'Ifac y Moraira- ocupan laderas en elevaciones junto al mar, y presentan por tanto un urbanismo geomórfico. Estos lugares tambien tienen una actividad comercial demostrada por el elevado número de importaciones, luego podemos hablar de la coexistencia de dos tradiciones urbanizadoras en el litoral: la propia de los poblados con urbanismo en ladera de la costa norte y los poblados con urbanismo regular en la costa meridional. Cabría preguntarse si esta diferente distribución geográfica no podría implicar diferencias culturales entre la población contestana.

\section{SOBRE LA DISPOSICIÓN INTERNA DE LOS POBLADOS}

Un avance importante de los últimos años en el campo de la arqueología ibérica ha sido la constatación de construcciones complejas o singulares en el interior de los poblados, y también el hecho de que algunas de estas estructuras fueran bastante antiguas. En cuanto a su finalidad, predominan las que se han interpretado como de tipo religioso, aunque también existen otras que corresponden a viviendas destacadas, quizá residencias aristocráticas.

En la Edetania, el edificio de carácter templario se encuentra en la capital, Sant Miquel de Llíria (Bonet et alii, 1990; Bonet, 1995, 364-366) (Fig. 12, 1). Se trata de un edificio excavado en la campaña de 1934 donde aparecieron la mayor parte de los vasos más conocidos del estilo Oliva-Llíria. Se trata de un edificio rectangular alargado -el núm. 14-, pavimentado con adobes en su parte central y con una piedra prismática a modo de estela sobre él. Este departamento se comunica a través de unos escalones con otro que lo pone en relación con el exterior -13-; uno de los lados está ocupado por un pozo cuadrado de dos metros de profundidad -12- en el que se hallaron numerosas cenizas y los citados vasos decorados. La distribución y uso de los espacios son los de un edificio de culto en el que los vasos decorados tienen una finalidad religiosa. Por otro lado, en Castellet de Bernabé y Puntal dels Llops tendríamos sendos ejemplos de capillas de culto doméstico, identificadas en estancias que no presentaban ninguna particularidad constructiva aunque sí objetos de uso litúrgico, como pebeteros de terracota o thymiateria, vasos importados para las libaciones, asador de bronce, exvotos, etc.

En la Contestania, destacan los templos de la Illeta dels Banyets del Campello y los posibles edificios de culto en El Oral y La Escuera. En el primero, citamos en primer lugar el llamado 'templo B' (Fig. 12, 2); corresponde a un recinto cuadrangular, con dos plataformas, sobre una de las cuales se ubicó una estela; en sucesivas refacciones se macizó el suelo, englobando incluso la estela, ya caída, y alzando un altar más complejo, en las inmediaciones del cual se encontraron un 'altar de cuernos' o quemaperfumes de piedra y un pebetero de terracota en forma de cabeza femenina. Nos encontramos ante dos objetos para la liturgia que confirmarían el carácter sacro de una construcción tipológicamente relacionada con prototipos fenicios y púnicos. También en Campello, el llamado 'templo A' es un edificio de tres naves con un pórtico dístilo y un vestíbulo común a las tres naves que conforman el cuerpo principal; la central, más ancha y larga que las laterales, se encuentra subdividida a su vez en dos en su parte final por medio de un muro perpendicular a la pared del fondo (Fig. 12, 2). Las considerables dimensiones del edificio y la complejidad de su planta permitieron suponer que se trataba de un edificio de carácter excepcional. E. Llobregat lo interpretó como un templo que reproduce modelos etruscos (Llobregat, 1983; 1984; 1985; 1988); en cualquier caso, se trata de un edificio importante que sigue el esquema de la casa tripartita tan frecuente en el mundo oriental -recuérdense las de Megiddo y Tell en Nasbeh, del siglo VII a.C. en el trabajo de Braemer (1982)-, y que existe también en el 
mundo etrusco itálico, donde según una tesis tradicional, desarrollada por Prayon (1975), las muy frecuentes tumbas con distribución tripartita no serían sino el reflejo de casas de planta similar. Pero plantas tripartitas se conocen también en el mundo ibérico peninsular: la tumba de Toya, por ejemplo, que, de aplicar el mismo principio que en el mundo etrusco, podría ser el reflejo de una casa de este tipo. Tripartito es también el célebre edificio de Cancho Roano (Almagro y Domínguez de la Concha, 1988-89; Celestino y Jiménez, 1993; Celestino, 1996), y tripartitas son también algunas casas particulares de poblados ibéricos.

En el barrio III de El Oral, se encuentra el edificio IIIJ, probablemente de culto (Fig. 12, 3 ). De su ubicación, con su entrada principal en una de las dos calles principales (calle III-IV) y rodeado de casas complejas (IIIG, IIIK, IVH), podemos deducir que ocupaba un lugar destacado en la trama urbana. El edificio consta de un único espacio rectangular, con una pequeña estancia-almacén a la izquierda de la puerta principal. Presenta un segundo acceso desde una plaza, a través de una puerta menor abierta en la pared oeste. El edificio se relaciona con el culto por el emblema con forma de lingote chipriota o piel de toro extendida dibujado en su pavimento con barros de color rojizo y verdoso (Abad y Sala, 1997). M. Almagro y T. Moneo $(2000,39)$ lo han interpretado como templo dinástico por su ubicación entre viviendas complejas. Como ha observado J. L. Escacena (2002, 67 ), el emblema de El Oral presenta una orientación hacia el este, hacia el orto solar del solsticio de verano, similar al que muestra el altar de la misma forma del santuario de Baal Saphon, en la Caura fenicia del s. VII a.C. (Coria, SeviIla). No obstante, el símbolo de El Oral guarda mayor parecido formal con el del santuario fenicio del Carambolo del s. VII a.C., en Sevilla, donde también aparece inserto en el pavimento de una estancia (Fernández y Rodríguez, 2005, 123, fig. 3), y no sobreelevado como el de Coria. La presencia del símbolo en El Oral es otro testimonio del arraigo oriental que fue cuajando en la depresión meridional alicantina desde que a fines del s. VIII a.C. los primeros comerciantes fenicios se instalaran en la desembocadura del Segura. La propuesta de los excavadores de Coria, sobre que el santuario fenicio estuviera dedicado a una divinidad poliada masculina, parece convincente, y abre una interesante perspectiva para comprender mejor el edificio de El Oral. También es interesante la hipótesis de M. C. Marín Ceballos $(2006,51-52)$ quien, partien- do de la misma documentación arqueológica, no acaba de ver una relación directa entre el signo de la piel de toro y un dios fenicio, sino un símbolo utilizado como insignia de poder en actos públicos -fundación de ciudades, cierre de pactos y acuerdos, contratos matrimoniales, etc.- por parte de la elite.

El edificio de La Escuera pertenece a otro momento más reciente de la cultura ibérica, puesto que el ajuar cerámico encontrado en su interior durante las excavaciones de 1960 data el final de su ocupación en los últimos años del s. III a.C. (Fig. 12, 4). La inexistencia de espacio de cocina, unas extrañas plataformas de barro, algunos tambores de columna en el departamento $\mathrm{f} y$ el hallazgo de vasos pintados únicos e inapropiados para usos domésticos, como el vaso de borde dentado o la jarra de asa trenzada y decoración metopada de hojas de hiedras, hizo pensar a su excavadora en un edificio de culto, interpretación que fue admitida. A diferencia de los sencillos edificios de carácter templario de Edeta y El Oral, el de La Escuera es un edificio complejo, con múltiples estancias construidas de una sola vez que responden a un plano preestablecido ${ }^{15}$. A juzgar por los hallazgos, las estancias parecen estar dedicadas a diversos usos, aunque ninguna de las excavadas puede ser señalada como la cella dado que no han aparecido por ahora exvotos u otros objetos estrictamente litúrgicos. Pese a que el edificio no fue excavado en su totalidad, lo que vamos conociendo de las estancias nos remite al concepto de santuario oriental compuesto por almacenes y espacios para actividades artesanales, además de los ámbitos sacros y de residencia sacerdotal. En ese sentido, el edificio de La Escuera guardaría mayor relación con el santuario del Cigarralejo, en el curso medio del río Segura, que con los templos mencionados.

Otro importante avance de la última década tiene que ver con las construcciones domésticas y la lectura social que se desprende de ellos. Debemos empezar con el primer intento de estructuración de las unidades de habitación realizado por E. Llobregat para la Contestania; este autor, al relacionar las estructuras del poblado de la Bastida, compuestas en su mayor par-

15. En la reciente campaña de excavaciones de 2007 hemos constatado que todos los muros intestan. Su construcción, empleando una fábrica cuidada, con profundos cimientos de mampostería y una primera hilada de grandes bloques escuadrados, es, además de única en la arquitectura ibérica, de una extremada solidez, tanto que se nos antoja una fábrica 'helenística'. 
te por dos departamentos, propuso, a partir del estudio de los materiales encontrados en cada uno de ellos, que estarían reflejando el lugar de habitación y de trabajo de un sexo concreto. La dependencia más próxima a la puerta, en la que con frecuencia aparecía un ajuar metálico, con herramientas y armas, podría ser un 'androceo', en tanto que la más al fondo, con cerámicas diversas, hogares e instrumentos de hilar y tejer, correspondería al 'gineceo'; pese a ello, el propio autor se refería a la posibilidad de que también podría suceder que el 'androceo' fuera el lugar de almacén y el establo, y el 'gineceo' el de habitación (Llobregat, 1972, 34-40), posibilidad esta última que, a juzgar por lo que conocemos de otros poblados ibéricos parece más razonable. Más adelante, Santos Velasco (1986a; 1986b) dio otra visión partiendo del mismo registro arqueológico al diferenciar almacenes de zonas de habitación.

En Castellet de Bernabé se identificó por primera vez una vivienda destacada en el sector oriental (Guérin, 2003, 260-264). Se trata de la vivienda $E$ : una gran casa de unos $170 \mathrm{~m}^{2}$ separada del resto del hábitat mediante un muro (Fig. $6,3)$. Su primera habitación estaba provista de varios hogares; las demás, de 15 a $17 \mathrm{~m}^{2}$ de superficie, correspondían, según el excavador, a la capilla antes mencionada, un molino y dos espacios dedicados a dormitorios y despensa; al sur, la casa contaba con un bloque cúbico de adobes que se interpreta como una especie de muelle para descargar los carros que llegaban hasta allí. Dado el carácter excepcional de esta casa, el gran espacio que ocupa dentro del poblado, la falta de lugares reservados para la producción, si exceptuamos el molino, y la voluntad de sus habitantes de separarse del resto de construcciones, el excavador defiende que se trata de la casa de una familia privilegiada, la del aristós del poblado. Frente a esta vivienda en la que habita probablemente una familia aristocrática extensa, el modelo recurrente de vivienda es el unicelular detectado a lo largo de la calle, en el que un espacio de $10-15 \mathrm{~m}^{2}$ sería suficiente para la vida de las familias nucleares que constituían la comunidad servil (Guérin, 2003, 336).

Una lectura similar se hace en la reciente publicación del fortín edetano del Puntal dels Llops (Bonet y Mata, 2002, 217-222). Como en el Castellet de Bernabé, el urbanismo de calle central condiciona la existencia de construcciones rectangulares sencillas abiertas a dicha calle (Fig. 6, 4). Sus ajuares han permitido clasificarlas según su función en varios tipos: estancias sin actividades específicas -posiblemente dormitorios-, actividades domésticas (molino y telares) y metalúrgicas, de preparación de alimentos, depósito de municiones (glandes), lugar de culto (gran número de bustos de terracota) y de posible celebración de actos públicos (thymiateria, vasos importados, asador, exvotos, etc.). Entre los departamentos, $\mathrm{H}$. Bonet y $\mathrm{C}$. Mata destacan el $\mathrm{n}^{\circ}$ 4 por ser el de ajuar más completo y rico, lo que señalaría la presencia de un personaje destacado, un guerrero propietario de un caballo, como indica el hallazgo de arreos de caballo y armas en su interior. Un aristócrata ecuestre, según defienden las autoras, que también es dueño de los medios de producción, pues en el dep. 4 han
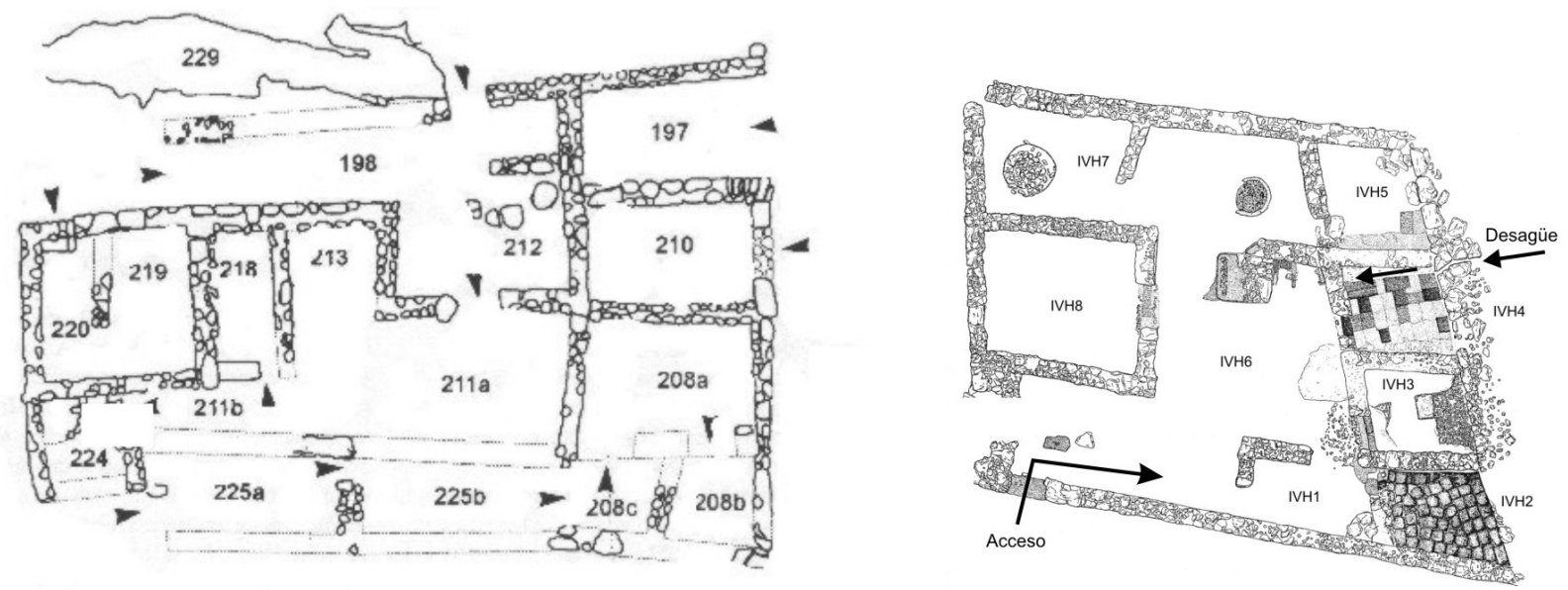

0 $3 m$

Figura 13: Residencias aristocráticas contestanas: 1. casa 10 de la Bastida (modificado a partir de Dies y Alvarez, 1998); 2. casa IVH de El Oral. 


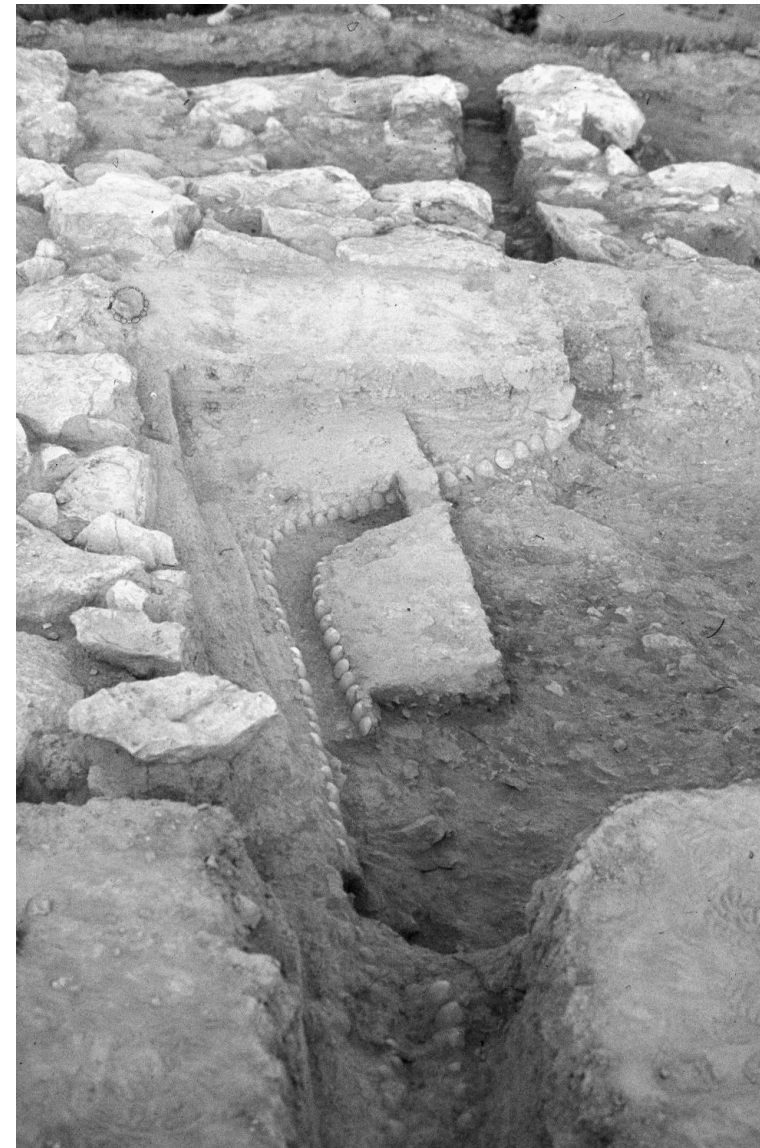

Figura 14: Canalillo de conchas del patio de la casa VIIID de El Oral.

aparecido ocho de los diecisiete instrumentos agrícolas hallados en el enclave. Las entre 20 y 60 personas que convivirían en el asentamiento no se agrupaban en 17 viviendas unifamiliares, sino en una "familia extensa", cuyos miembros estarían unidos por lazos de parentesco y de clientelismo. Una estructura social similar a la de Castellet de Bernabé y que, sin embargo, como apostillan Bonet y Mata $(2002,221)$, no se refleja a nivel urbanístico separando la familia aristocrática su vivienda del resto de la comunidad.

En la Bastida, el edificio 10 ha sido identificado como una residencia con posible función palacial (Dies y Álvarez, 1998), a juzgar por una serie de rasgos valorados por los investigadores como destacados (Fig. 13, 1). De un lado, esta vivienda alcanza una superficie mayor que la del resto de las casas; de otro, posee la única cisterna existente en el poblado; y por último, el hallazgo en su interior de materiales destacables, como el bronce del Guerrer de Moixent. La residencia, además, presentaba buenos acabados interiores, como se deduce del registro de enlu- cidos de cal y pintura mural. Por todo ello, resulta admisible que pueda tratarse de una residencia aristocrática.

Otro caso de estudio en esta misma línea lo proporciona el poblado antiguo de El Oral, donde las diferencias de extensión entre las viviendas son un indicador claro de distinción social en la comunidad. Las casas más sencillas estaban constituidas por dos estancias que, sin exceder de una veintena de $\mathrm{m}^{2}$, eran suficientes para el desarrollo de la vida cotidiana de una familia nuclear. Directamente desde la calle se accedería a la primera estancia y principal; en ella, un hogar centrado señalaba el espacio donde se vivía y se llevaban a cabo las funciones domésticas. Desde esta estancia se accedería a otra más pequeña al fondo, un almacén en algunos casos (casas IIIC y IIID), y también zona de reposo en otros (casas IVE y IVF) (Fig. 11, 1).

Consideramos casas complejas las que superan el espacio doméstico básico de dos ambientes y pueden alcanzar hasta 11 estancias, como la casa IIIK. En ellas también existe un espacio de cocina aparentemente sin diferencia de las casas sencillas y con un departamento anejo de almacenaje, pero el mayor número de estancias, algunas vacías, otras equipadas con bancos corridos, que podían servir indistintamente para el almacenaje y como ambientes de reposo, y donde no hay indicios de que se llevaran a cabo actividades domésticas o artesanales, apunta a familias extensas. La multiplicación de estancias vacías, probablemente de reposo, va en ese sentido, pues puede deberse a que en la familia existe más de una mujer adulta. Así se propone en Castellet de Bernabé, cuando en la vivienda del aristócrata se constatan telares en cuatro estancias distintas, que podría señalar la presencia de cuatro mujeres en edad de tejer (Guérin, 2003, 333). Aunque esta abundancia de telares en una sola casa no se constata en El Oral, no cabe duda de que las casas complejas con muchas estancias responden a un estatus social y económico elevado. Es posible que en algunas de esas estancias vacías se desarrollaran actividades de carácter más público, como podía ser el caso de la estancia 8 de la casa IVH (Fig. 13, 2), que ocupa una ubicación destacada dentro de la vivienda, en el centro del patio.

Entre las casas complejas, aquellas con patio adosadas al lienzo oriental de la muralla las interpretamos como residencias más destacadas por sus características arquitectónicas y constructivas, fundamentalmente por su propia distribución en torno a un patio cerrado a la 


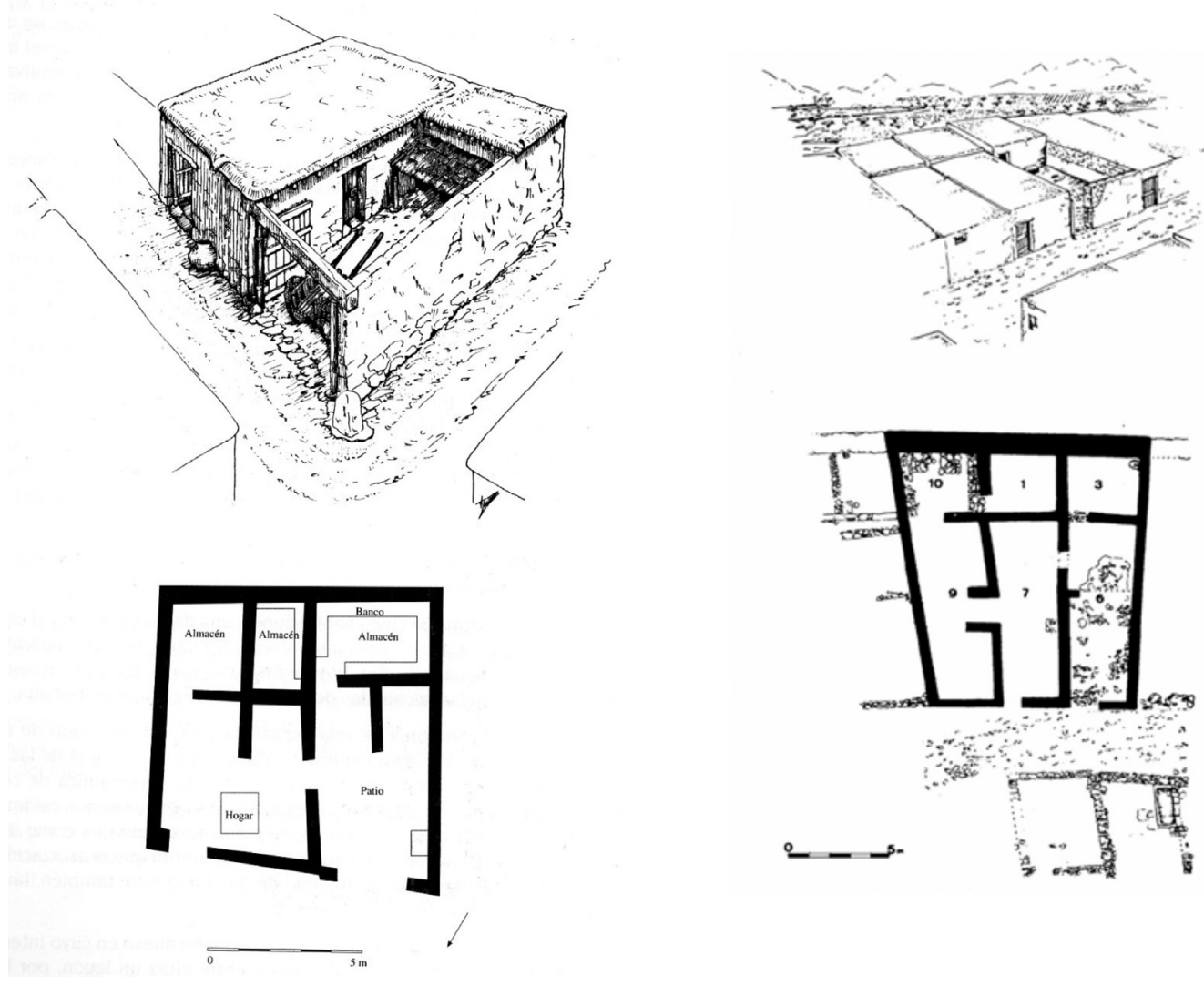

Figura 15: Casas de agricultores: 1. Los Villares; 2. La Seña (recreaciones de H. Bonet y C. Mata).

calle y porque la existencia de desagües que atraviesan la muralla (Fig. 14) para evacuar el agua de lluvia, denota un importante grado de planificación urbana. De entre ellas, la casa IVH es la que reune todas las condiciones para ser clasificada como una residencia aristocrática (Sala y Abad, 2006), al igual que la casa 10 de la Bastida. Además de su tamaño, los buenos acabados interiores -buenos enlucidos con pintura mural, preparados de pavimentos hechos de enlosados de adobe o de guijarros-, los hallazgos en su interior de piezas destacadas y la distribución en torno a un patio, la señalan como una vivienda destacada. A nuestro juicio, el dato más relevante es el hecho de que el patio esté cerrado a la calle y tenga un acceso en $\mathrm{L}$ que impide totalmente la visión desde el exterior. Con ello, la familia extensa que ocupaba la vivienda IVH pretendía preservar su intimidad para, de alguna manera, distinguirse del resto de la comunidad. En este hecho creemos ver reflejado un concepto arquitectónico y social de privacidad mediterráneo y oriental. Estas casas con patio de El Oral constituyen el registro más antiguo en la cultura ibérica y su antecedente más próximo lo tenemos en las casas de tapial de la fase fun- dacional fenicia de la Fonteta (Rouillard et alii, 2007).

En cuanto a la situación de las casas sencillas y complejas en el tejido urbano, con el área descubierta hasta ahora en El Oral no podemos afirmar que exista una distribución diferencial. Las casas sencillas no ocupan un espacio reservado, sino que aparecen entre las casas complejas. La concentración de las casas con patio junto al lienzo oriental de la muralla entra dentro de lo lógico, aunque no podemos descartar que fuera un sector privilegiado dentro del enclave -por ejemplo por razones higiénicas- hasta que no se excaven las casas adosadas al lienzo opuesto de la muralla. Es todavía prematuro debatir sobre si esta distribución puede ser indicio o no de una sociedad con estamentos muy diferenciados. La lectura de este contexto urbanìstico y arquitectónico deja ver una comunidad con distinciones sociales, pero creemos que todavía no permite afinar en la diferenciación de niveles en la jerarquía de las relaciones clientelares propuestas por A. Ruiz (1998, 293).

La lectura social del registro arquitectónico presenta otras facetas, además de la distinción de rango, como puede ser la distinción de géne- 
ro $^{16}$ o la interpretación del oficio u ocupación de los habitantes de las viviendas, para lo cual el análisis microespacial del registro arqueológico es primordial. El poblado de Los Villares (Caudete de las Fuentes, València) ha proporcionado una gran construcción de unos $100 \mathrm{~m}^{2}$, formada por dos cuerpos comunicados por un vano de 1 $\mathrm{m}$. En el oriental, una gran estancia con hogar da paso en su fondo a un par de dependencias con bancos corridos; en el occidental, un gran espacio abierto a la calle a través de una puerta de $2 \mathrm{~m}$ tiene al fondo otra estancia provista de bancos corridos en sus cuatro paredes (Mata, 1991, 23-24) (Fig. 15, 1). El hecho de que se interprete como un espacio para albergar un carro y la estancia al fondo como un almacén ha hecho pensar a los autores en una casa cuyos ocupantes se dedican a labores agrícolas. También se interpreta como una vivienda de agricultores la casa de $170 \mathrm{~m}^{2}$ de La Seña (Bonet, 2000), cuya ubicación y superficie de almacenes, o la distribución general de los espacios, son muy parecidos a los de la casa de Los Villares (Fig. 15, 2). Otra vivienda interesante según esta perspectiva de análisis es la ocupada por los departamentos 45 a 56 de la Bastida, ya que su contexto material demuestra la ocupación de sus habitantes como artesanos metalúrgicos, actividad que compaginarían con la agricultura (Bonet y Guérin, 1995, 100).

Con todo, la lectura social y económica del registro arquitectónico ibero no parece haber agotado todas sus posibilidades, porque siguen apareciendo nuevos ejemplos, como el del Perengil de Vinaròs, una vivienda-torre aislada, sólidamente construida, se diría que fortificada, y que indistintamente puede ser interpretada tanto como lugar de vigilancia de caminos como lugar de culto territorial; son casos difíciles de encajar en los modelos de organización espacial al uso que necesariamente obligan a estar abiertos a nuevas perspectivas.

Prof. Lorenzo Abad Casal
Profa. Feliciana Sala Sellés
Dpto. de Prehistoria, Arqueología,
Ha Antigua, Filología Griega y $^{\text {Filología Latina }}$
Universidad de Alicante
030080 Alicante
lorenzo.abad@ua.es
feliciana.sala@ua.es

16. Cf. Las recientes reflexiones de P. Guérin (2005) acerca de la concurrencia de telares y molinos como marcadores de género en la Contestania y Edetania.

\section{BIBLIOGRAFÍA}

ABAD CASAL, L., 1984: «La Romanización», en Alcoy. Prehistoria y Arqueología. Cien años de investigación, Alcoi.

ABAD CASAL, L., 1987a: "El poblamiento ibérico en la provincia de Alicante", en Iberos. Actas de las Primeras Jornadas sobre el Mundo Ibérico (Jaén, 1985), Jaén.

ABAD CASAL, L., 1987b: "Cultura Ibérica", en Historia General de España y América, I, 2, 171-253, Madrid.

ABAD CASAL, L., 1992: «Las culturas ibéricas del área suroriental de la Península», en Primera Reunión sobre Paleoetnología de la Península Ibérica (Madrid, 1989), Complutum, 2-3, 151-166.

ABAD, L. y BENDALA, M., 1990: El Arte ibérico, Historia del Arte de Historia 16, núm. 10, Madrid.

ABAD, L. y SALA, F., 1993: El poblado ibérico de El Oral (San Fulgencio, Alicante), T.V. del S.I.P., 90, València.

ABAD, L. y SALA, F., 1997: "Sobre el posible uso cúltico de algunos edificios de la Contestania Ibérica", Quaderns de Prehistòria i Arqueologia de Castelló, 18, 91-102.

ABAD, L.; SALA, F.; GRAU, I; MORATALLA, J.; PASTOR, A. y TENdero, M., 2001: Poblamiento ibérico en el Bajo Segura: El Oral (II) y La Escuera, Bibliotheca Archaeologica Hispana, 12, Real Academia de la Historia, Madrid.

ABAD, L. y SANZ, R., 1995: "La cerámica ibérica con decoración figurada de la provincia de Albacete. Iconografía y territorialidad", Saguntum, 29, 73-84.

ALLEPUZ MARZÀ, X., 2001: Introducció al poblament ibèric a la Plana de l'Arc, Col·lecció Universitària Geografia i Historia, Castelló.

ALMAGRO GORBEA, M. y DOMINGUEZ DE LA CONCHA, A., 1988-89: "El palacio de Cancho Roano y sus paralelos arquitectónicos y funcionales”, Zephyrus, 41-42, 339-82.

ALMAGRO GORBEA, M. y MONEO, T., 2000: Santuarios urbanos en el mundo ibérico, Real Academia de la Historia, Madrid.

ARASA GIL, F., 2001: La romanització a les comarques septentrionals del litoral valencià: poblament ibèric $i$ importacions itàliques en els segles II-I aC, T.V. del S.I.P., 100, València.

ASENSIO ESTEBAN, J. A., 1995: La Ciudad en el Mundo Prerromano en Aragón, Caesaraugusta, 70, Zaragoza.

AZUAR, R.; ROUILLARD, P.; GAILLEDRAT, E.; MORET, P.; SALA, F. y BADIE, A., 1998: "L'établissement orientalisant et ibérique ancien de "La Rábita", Guardamar del Segura (Alicante, Espagne). Première et seconde campagnes de fouille, juin 1996 et avril 1997", Trabajos de Prehistoria, 55: 2, 111-126.

AZUAR, R.; ROUILLARD, P.; GAILLEDRAT, E.; MORET, P.; SALA, F. y BADIE, A., 2000: "L'établissement orientalizant et ibérique ancien de La Rábita, Guardamar del Segura (Alicante). Première et seconde campagnes de fouilles 1996-1998", Scripta in Honorem Enrique Llobregat, I, 265285, Alicante.

BADIE, A.; GAILLEDRAT, E.; MORET, P; ROUILLARD, P.; SANCHEZ, M.J. y SILLIERES, P., 2000: Le site antique de La Picola à Santa Pola (Alicante, Espagne), Editions Recherche sur les Civilisations-Casa de Velázquez, París.

BARRIER, P. y MONTENAT, C., 2007: « Le paysage de l'époque protohistorique à l'embouchure du Segura. Approche paléogéographique », en P. Rouillard et alii (eds.): L'établissement protohistorique de La Fonteta (fin VIIle - fin Vle siècle av. J._C.), Collection de la Casa de Velázquez, 96, 7-21, Madrid.

BELARTE FRANCO, C., 1997: Arquitectura doméstica i estructura social a la Catalunya protohistòrica, Arqueo-Mediterránia, 1, Barcelona. 
BERNABÉU, J.; BONET, H.; GUERIN, P. y MATA, C., 1986: «Análisis microespacial del poblado ibérico del Puntal dels Llops (Olocau, Valencia), Coloquio sobre el Microespacio, Arqueología Espacial IX, 321-337, Teruel.

BERNABEU, J.; BONET, H. y MATA, C., 1987: "Hipótesis sobre la organización del territorio edetano en época ibérica plena: el ejemplo del territorio de Edeta/Llíria", Iberos. Actas de las I Jornadas sobre el Mundo Ibérico (Jaén, 1985), 137-156, Jaén.

BLANCO, A. y ABAD, L., 1988: Los iberos, Historias del Viejo Mundo, núm. 16, Madrid.

BOLUFER, X.; SALA, F. y GRAU, I., e.p.: "Una torre d'aguait ibèrica al Tossal de l'Empedrola (Calp, Marina Alta)", Xàbiga.

BONET ROSADO, H., 1995: El Tossal de Sant Miquel de Lliria. La antigua Edeta y su territorio, València.

BONET ROSADO, H., 2000: "Un nivel del ibérico antiguo en La Seña (Villar del Arzobispo, Valencia)", Scripta in Honorem Enrique Llobregat, I, 307-324, Alicante.

BONET, H. y GUERIN, P., 1995: "Propuestas metodológicas para la definición de la vivienda ibérica en el área valenciana", Ethno-Archéologie méditerranéenne. Finalités, démarches et résultats, Collection de la Casa de Velázquez, 54, 85-104, Madrid.

BONET, H. y MATA, C., 1981: El Puntal dels Llops, (Olocau, Valencia), T.V. del S.I.P., 71, València.

BONET, H. y MATA, C., 2000: "Habitat et territoire au Premier Âge du Fer en Pays Valencien", Mailhac et Le Premier Âge du Fer en Europe Occidentale. Homages a Odette et Jean Taffanel (Carcassonne, 1997), 61-72, Lattes.

BONET, H. y MATA, C., 2001: "Organización del territorio y poblamiento en el País Valenciano entre los siglos VII al II a.C.", en L. Berrocal y Ph. Gardes (eds.): Entre celtas e iberos. Los poblamientos protohistóricos de las Galias e Hispania, 175-186, Madrid.

BONET, H. y MATA, C., 2002: El Puntal dels Llops. Un fortín edetano, T.V. del S.I.P., 99, València.

BONET, H. Y MATA, C. y GUÉRIN, P., 1990: "Cabezas votivas y lugares de culto edetanos", Verdolay, 2, 185-199.

BONET, H.; VIVES-FERRÁNDIZ, J. y CARUANA, I., 2005: "La Bastida de les Alcusses (Moixent, Valencia). Investigación y musealización", Actas de las Jornadas de Arqueología Ibérica Contestania ibérica, treinta años después, 267-279, Alicante.

BRAEMER, F., 1982 : L'architecture domestique du Levant a l'Age du Fer, París.

CASTELLANO, J. J.; SÁEZ, M. J. y SÁEZ, A., 2005: "Materiales contestanos del Museo Arqueológico Municipal de Enguera", Actas de las Jornadas de Arqueología Ibérica Contestania ibérica, treinta años después, 199-209, Alicante.

CELESTINO PÉREZ, S. y JIMENEZ AVILA, F., 1993: El palacio-santuario de Cancho Roano IV. El sector Norte, Badajoz.

CELESTINO PÉREZ, S. (ed.), 1996: El palacio-santuario de Cancho Roano. Roano V-VI-VII. Los sectores oeste, sur $y$ este, Badajoz.

DIES, E. y ÁLVAREZ, N., 1998: "Análisis de un edificio con posible función palacial: la casa 10 de la Bastida de les Alcusses (Moixent)", Congrés Internacional Els ibers. Prínceps d'Occident, 327-341, Barcelona.

ESCACENA, J. L., 2002: "Dioses, Toros y Altares. Un templo para Baal en la antigua desembocadura del Guadalquivir", en E. Ferrer (ed.), Ex Oriente Lux: las religiones orientales antiguas en la Península Ibérica, Monografía Revista Spal, 2, 33-75, Sevilla.
ESTÉVEZ, A. y PINA, J., 1984: "Dunas, playas y marjales del Cuaternario en el litoral sur de la provincia de Alicante", en Escarré et alii, Estudios sobre el medio ambiente y biocenosis en los arenales costeros de la provincia de Alicante, Alicante.

FERNÁNDEZ GUTIÉRREZ, J. C., 1986: «Paleolíneas de la costa del Sureste español desde el Plioceno al Cuaternario Reciente», en Historia de Cartagena, III, Murcia.

FERNÁNDEZ FLORES, A. y RODRÍGUEZ AZOGUE, A., 2005: "El complejo monumental del Carambolo Alto, Camas (Sevilla). Un santuario orientalizante en la paleodesembocadura del Guadalquivir", Trabajos de Prehistoria, 62, $\mathrm{n}^{\circ} 1,111-138$.

FLETCHER, D.; PLA, E. y ALCÁCER, J., 1965: La Bastida de Les Alcuses (Mogente, Valencia), I, València,

FLETCHER, D.; PLA, E. y ALCÁCER, J., 1969: La Bastida de Les Alcuses (Mogente, Valencia), II, València.

GARCÍA GANDÍA, J. R. y MORATALLA JÁVEGA, J., 199899: "Nuevos datos sobre arquitectura de prestigio ibérica. La regia de "Las Tres Hermanas" (Aspe, Alicante)", Lucentum, XVII-XVIII, 163-182.

GARCÍA MENÁRGUEZ, A., 1995: "El Cabezo Pequeño del Estaño, Guardamar del Segura. Un poblado protohistórico en el tramo final del río Segura", Symposium Internacional sobre Sociedad y Cultura Púnica en España, 269280, Cartagena.

GONZÁLEZ PRATS, A., 1999: La Fonteta, 1996-1998. El emporio fenicio de la desembocadura del río Segura, Catàleg de l'exposició, Guardamar del Segura.

GONZÁLEZ, A.; RUIZ, E. Y GARCÍA, A., 1999: "La Fonteta, 1997. Memoria preliminar de la segunda campaña de excavaciones ordinarias en la ciudad fenicia de la desembocadura del río Segura, Guardamar (Alicante)", La cerámica fenicia en occidente. Centros de producción y áreas de comercio, 257-301, Alicante.

GRAU MIRA, I., 2002: La organización del territorio en el área central de la Contestania Ibérica, Publicacions de la Universitat d'Alacant.

GUÉRIN, P., 2003: El Castellet de Bernabé y el horizonte ibérico pleno edetano, T.V. del S.I.P., 101, València.

GUÉRIN, P., 2005: "ideología y género en Contestania y Edetania", Actas de las Jornadas de Arqueología Ibérica Contestania ibérica, treinta años después, 259-266, Alicante.

HERNÁNDEZ, L. y SALA, F., 1996: El Puntal de Salinas. Un hábitat ibérico del siglo IV aC en el Alto Vinalopó, Villena.

LILLO, P., 1981: El poblamiento ibérico en la provincia de Murcia, Murcia.

LLOBREGAT, E. A., 1972: Contestania ibérica, Alicante.

LLOBREGAT, E. A., 1983: "El templo ibérico de la llleta dels Banyets”, en J.M. Blázquez, Primitivas religiones ibéricas, II. Religión prerromanas, cap. IV, 489-498, Madrid.

LLOBREGAT, E. A., 1984: "Un altar de perfumes de tipo oriental en el yacimiento ibérico de la llleta dels Banyets (el Campello, Alicante)", Boletín de la Sociedad Española de Orientalistas, XX, 301-305.

LLOBREGAT, E. A., 1985: "Dos temples ibèrics a l'interior del poblat de l'illeta dels Banyets", Fonaments, 5, 103-112.

LLOBREGAT, E. A., 1988: "Un conjunto de templos ibéricos del siglo IV a.C. hallado en las excavaciones de la isla de Campello (Alicante)2, Homenaje a Samuel de los Santos, 137-143, Albacete.

LLOBREGAT, E. A.; CORTELL, E.; JUAN, J. y SEGURA, J. M., 1992: "El urbanismo ibérico en la Serreta", Recerques del Museu d'Alcoi, 1, 37-70.

MARÍN CEBALLOS, M. C., 2006: "De dioses, pieles y lingotes", Habis, 37, 35-53. 
MARTÍ BONAFÉ, M. A., 1998: El área territorial de ArseSaguntum en época ibérica, Estudios Universitarios, 72, València.

MAS, J., 1980: "El sureste protohistórico", Historia de la provincia de Murcia, 121-175, Murcia.

MATA PARREÑO, C., 1991: Los Villares (Caudete de las Fuentes, Valencia): origen y evolución de la Cultura Ibérica, T.V. del S.I.P., 88, València.

MORATALLA JÁVEGA, J., 2005: "El territorio meridional de la Contestania", Actas de las Jornadas de Arqueología Ibérica Contestania ibérica, treinta años después, 91-117, Alicante.

NORDSTRÖM, S., 1967: Excavaciones en el poblado ibérico de La Escuera, Alicante, T.V. del S.I.P., 34, València.

OLCINA DOMÉNECH, M. (ed.), 1997: La Illeta dels Banyets (El Campello, Alicante). Estudios de la Edad del Bronce y Época Ibérica, Museu Arqueològic Provincial d'Alacant: Sèrie Major, 1, Alacant.

OLCINA DOMÉNECH, M., 2005: "La Illeta dels Banyets, el Tossal de Manises y la Serreta", Actas de las Jornadas de Arqueología Ibérica Contestania ibérica, treinta años después, 145-177, Alicante.

OLCINA, M.; GRAU, I. y MOLTÓ, S., 2000: "El sector I de la Serreta: noves perspectives al voltant de l'ocupació de l'assentament", Recerques del Museu d'Alcoi, 9, 119144.

OLCINA, M.; GRAU, I.; MOLTÓ, S.; REIG, C.; SALA, F. y SEGURA, J. M., 1998: "Nuevas aportaciones a la evolución de la ciudad ibérica: el ejemplo de La Serreta", Congrés Internacional Els Ibers. Prínceps d'Occident, 35-46, Barcelona.

OLIVER FOIX, A., 1994: El poblado ibérico del Puig de la Misericordia de Vinaròs, Vinaròs.

OLIVER FOIX, A., 1996: Poblamiento y territorio protohistóricos en el llano litoral del Baix Maestrat (Castellón), Castelló.

OLIVER FOIX, A., 2001: Un peculiar edificio ibérico: el Perengil (Vinaròs, Castellón), Monografies de Prehistòria i Arqueologia Castellonenques, 6, Castelló.

OLIVER FOIX, A. 2006: El Puig de la Nau de Benicarló, Castelló.

OLIVER, A. y GUSI, F., 1995: El Puig de la Nau. Un hábitat fortificado ibérico en el ámbito mediterráneo peninsular Castelló.

PEÑA, J., TEIXIDÓ, T., ABAD, L. y SALA, F., 2007: "Prospecciones electromagnéticas en la Escuera", Congreso Internacional de Arqueometría. Sevilla.

PÉREZ BALLESTER, J. y BORREDÀ, R., 1998: "El poblamiento ibérico del Valle del Cànyoles. Avance de un proyecto de evolución del paisaje en la comarca de la Costera (Valencia)", Saguntum, 31, 133-154.

PLA BALLESTER, E., 1980: "Introducción”, en Nuestra Historia, València

PRAYON, F., 1975: Frühetruskische Grab- und Hausarchitektur, Heidelberg.

RAGA RUBIO, M., 1996: "Sobre el urbanismo del poblado ibérico de "La Covalta" (Agres, Alicante y Albaida, Valencia). Nueva planimetría", XXIII C.N.A., 433-440, Elx.
RODRÍGUEZ TRAVER, A. y PÉREZ BALLESTER, J., 2005 "El poblamiento ibérico antiguo en el valle del río Cànyoles (la Costera, València)", Actas de las Jornadas de Arqueología Ibérica Contestania ibérica, treinta años después, 211-225, Alicante.

ROS, M., 1980: "La cultura ibérica", Historia de la provincia de Murcia, 178-275, Murcia

ROSSER, P., 2007: El yacimiento arqueológico del Tossal de les Basses. Seis mil años de historia de Alicante. Alicante.

ROUILLARD, P. ; GAILLEDRAT, E. y SALA, F. (eds.), 2007 : L'établissement protohistorique de La Fonteta (fin VIIle fin Vle siècle av. J. C.), Collection de la Casa de Velázquez, 96, Madrid.

RUIZ RODRÍGUEZ, A., 1998: "Los príncipes iberos: procesos económicos y sociales", Actas del Congreso Internacional Los Iberos. Príncipes de Occidente, 285-300, Barcelona.

SALA SELLÉS, F., 1990: "El poblado ibérico de Cap Negret (Altea, Alicante)", Memòries Arqueològiques a la Comunitat Valenciana, II, 20-22, València.

SALA SELLÉS, F., 1995: La Cultura Ibérica de las comarcas meridionales de la Contestania entre los siglos VI y III aC. Una propuesta de evolución, Colllecció Textos Universitaris, Alacant.

SALA SELLÉS, F., 2001-2002: "Para una revisión de las relaciones púnicas con la costa ibérica alicantina: nuevas perspectivas sobre algunos viejos problemas", Anales de Prehistoria y Arqueología de la Universidad de Murcia, 1718, 283-300.

SALA, F. y ABAD, L., 2006: "Arquitectura monumental y arquitectura doméstica en la Contestania”, Lucentum, XXV, 23-46.

SALA, F.; GRAU, I.; OLCINA, M. y MOLTÓ, J., 2004: "El comerç d'àmfores en època protohistòrica i ibèrica a les terres de la Contestània", II Reunió Internacional d'Arqueologia de Calafell El comerç amfòric protohistòric a la Mediterrània occidental (segles VII-III aC.), Sèrie Arqueo-Mediterrània, 8, 229-251, Barcelona.

SANTOS VELASCO, J. A., 1986a: "Ensayo de estudio espacial sobre los materiales de La Bastida de Les Alcuses (Valencia)", Trabajos de Prehistoria, 239-255;

SANTOS VELASCO, J. A., 1986b: "Vivienda y distribución desigual de la riqueza en La Bastida de Les Alcuses (Valencia)", Arqueología espacial. Coloquio sobre el Microespacio, 9, 339-48, Teruel.

TARRADELL, M., 1985: "El poblat ibèric del Tossal de la Cala de Benidorm. Notes d'excavació", Fonaments, 5, 113127.

VALL DE PLA, M. A., 1971: El poblado ibérico de Covalta (Albaida, Valencia), T.V. del S.I.P., 41, València,

UROZ, J., 1981: La Contestania ibérica: economía y sociedad, Alicante.

UROZ, J., 1983: La Regio Edetania en época ibérica, Alicante.

UROZ, J., 1985: "La época ibérica", Historia de la Provincia de Alicante, 170-220, Alicante. 